\title{
A role of the Atlantic Ocean in predicting summer surface air temperature over North East Asia?
}

\author{
Paul-Arthur Monerie ${ }^{1}$ (1) $\cdot$ Jon Robson $^{1} \cdot$ Buwen Dong $^{1} \cdot$ Nick Dunstone $^{2}$
}

Received: 24 May 2017 / Accepted: 20 September 2017 / Published online: 5 October 2017

(c) The Author(s) 2017. This article is an open access publication

\begin{abstract}
We assess the ability of the DePreSys3 prediction system to predict the summer (JJAS) surface-air temperature over North East Asia. DePreSys3 is based on a high resolution ocean-atmosphere coupled climate prediction system $(\sim 60 \mathrm{~km}$ in the atmosphere and $\sim 25 \mathrm{~km}$ in the ocean), which is full-field initialized from 1960 to 2014 (26 start-dates). We find skill in predicting surface-air temperature, relative to a long-term trend, for 1 and 2-5 year leadtimes over North East Asia, the North Atlantic Ocean and Eastern Europe. DePreSys3 also reproduces the interdecadal evolution of surface-air temperature over the North Atlantic subpolar gyre and North East Asia for both lead times, along with the strong warming that occurred in the mid-1990s over both areas. Composite analysis reveals that the skill at capturing interdecadal changes in North East Asia is associated with the propagation of an atmospheric Rossby wave, which follows the subtropical jet and modulates surface-air temperature from Europe to Eastern Asia. We hypothesise that this 'circumglobal teleconnection' pattern is excited over the Atlantic Ocean and is related to Atlantic multi-decadal variability and the associated changes in precipitation over the Sahel and the subtropical Atlantic Ocean. This mechanism is robust for the $2-5$ year lead-time. For the 1 year lead-time the Pacific Ocean also plays an important role in leading to
\end{abstract}

Electronic supplementary material The online version of this article (doi:10.1007/s00382-017-3935-z) contains supplementary material, which is available to authorized users.

Paul-Arthur Monerie

pmonerie@gmail.com

1 National Centre for Atmospheric Science (NCAS), Department of Meteorology, University of Reading, Reading, UK

2 Met Office Hadley Centre, Exeter, UK skill in predicting SAT over Northeast Asia. Increased temperatures and precipitation over the western Pacific Ocean was found to be associated with a Pacific-Japan like-pattern, which can affect East Asia's climate.

\section{Introduction}

Simulations performed with Ocean-Atmosphere General Circulation Models (OAGCM) under the Climate Model Intercomparison Project, phase 5 (CMIP5) (Taylor et al. 2012), provide climate predictions for the upcoming 100 years (the so-called radiative concentration pathways emission scenarios). However, CMIP simulations suffer from severe limitations in predicting climate at a shorttime horizon ( $<10$ years), as highlighted by the "hiatus" in global-mean surface temperature rise (Watanabe et al. 2013; Kosaka and Xie 2013; Meehl et al. 2014). To fill this gap, initialized near-term (or decadal) prediction systems have been developed (Meehl et al. 2009) to provide better predictions than uninitialized simulations (Bellucci et al. 2013; Karspeck et al. 2015) on seasonal-to-decadal timescales. Decadal prediction systems are initialized frequently (generally from every year to every 5 years) to improve the simulation of internal variability. The added value of the initialization stands out over the North Atlantic Ocean where an accurate initialization of the Atlantic Meridional Overturning Circulation (AMOC) is thought to allow Atlantic Multidecadal Variability (AMV) to be predicted years in advance (Griffies and Bryan 1997; Boer 2000; Collins et al. 2006; Pohlmann et al. 2013). Thus, near-term climate prediction systems are useful tools to provide predictions at interannual-to-decadal timescales, which are helpful to calibrate plans and actions related to climatic events due to 
climate variability and change (Hibbard et al. 2007; Cox and Stephenson 2007).

An additional motivation for using initialized decadal predictions comes from various studies that have successfully predicted regional climate on decadal time scales (Smith et al. 2007; Keenlyside et al. 2008; Pohlmann et al. 2009; Mochizuki et al. 2012; Bellucci et al. 2013, 2015; Chikamoto et al. 2013; Doblas-Reyes et al. 2013; Karspeck et al. 2015; García-Serrano et al. 2015; Monerie et al. 2017). The skill in predicting climate is primarily determined by the external forcing (i.e. the increase in the atmospheric wellmixed greenhouse gas concentration), especially for leadtimes greater than 2 years (van Oldenborgh et al. 2012). Major volcanic events induce an abrupt cooling through the ejected volcanic aerosols (Guemas et al. 2013; Mehta et al. 2013) and are also a source of additional skill in retrospectively predicting temperature (Timmreck et al. 2016). The skill found in hindcasts owing to volcanic eruptions is however artificial since these events cannot be predicted, as highlighted by Meehl et al. (2009). The second source of skill is due to the Ocean initialization, that can lead to additional skill, especially for the first years of the hindcasts (Yeager et al. 2012; Robson et al. 2012; Matei et al. 2012; Chikamoto et al. 2013; Doblas-Reyes et al. 2013; Monerie et al. 2017).

The skill in predicting SAT over land is generally weaker than for the SSTs (as seen in Bellucci et al. 2013; among others) and oceanic heat content (Chikamoto et al. 2013) because SAT changes are associated with stochastic perturbations of the atmosphere while SST is associated with the higher inertia of the Ocean. However, predicting SAT and precipitation over land is of particular interest for decision makers. Besides the impact of external forcings, evidence suggests that skill in predicting precipitation and SAT years ahead is linked to the ability of a climate model to simulate the interdecadal evolution of the SSTs and their associated remote impacts over land. For instance, high skill in predicting the West African Monsoon (WAM) evolution can be found due to a high skill in predicting the AMV (Gaetani and Mohino 2013; Mohino et al. 2016; Sheen et al. 2017). More precisely Sheen et al. (2017) have shown that the DePreSys3 prediction system is able to predict the multidecadal evolution of the WAM, including the large drought of the 70s and 80 s and the recovery of the 90 s, due to the SST change over the North Atlantic Ocean and the Mediterranean Sea. The skill is thereby due to the ability of models to simulate the remote impact of the SSTs on a decadal time-scale. Such a mechanism implies predicting precipitation and SAT over land owing to the potential predictability of the North Atlantic Ocean temperature.

SAT warmed substantially in North East Asia (NEA) during the mid-1990s, and more strongly than over the surrounding regions (Chen and Lu 2014), along with a decrease in precipitation (Zhu et al. 2011; Qi and Wang
2012; Chen and $\mathrm{Lu} 2014)$. The warming was about $1{ }^{\circ} \mathrm{C}$ in summer, which is larger than the standard deviation of summer SAT over NEA $\left(0.6^{\circ} \mathrm{C}\right)$, implying a strong signal-to-noise ratio and is therefore an interesting case study to test the ability of a prediction system to predict SAT over land. The warming over NEA has been linked to a circulation change; In particular, a positive anomaly of upper-level geopotential height (Zhu et al. 2011, 2012; Chen and Lu 2014). The change in atmospheric circulation is thought to have been influenced by remote SSTs. For example, Wu et al. (2016a, b) and Lin et al. (2016) have highlighted that the north Atlantic Ocean can influence East Asian climate through the modulation of the atmosphere by a Rossby wave that propagates eastward along the northern Hemisphere, leading to a SAT change over East Asia. This mechanism is called the circumglobal teleconnection (CGT) pattern and is one of the two dominant modes of the North Hemisphere extratropical upper-tropospheric atmospheric variability (Ding and Wang 2005). At the interannual time-scale the CGT pattern is associated with the El-Niño Southern Oscillation and the Indian summer monsoon (Ding and Wang 2005; Lin 2009; Ding et al. 2011) while at the interdecadal time-scale the CGT pattern is associated with the North Atlantic Ocean (Wu et al. 2016a; Lin et al. 2016). The wave-like structure of the CGT pattern is maintained by extratropical atmospheric internal dynamics (Yasui and Watanabe 2009; Ding et al. 2011). This mechanism may be very relevant for the recent NEA warming since Qian et al. (2014) have reported that the influence of the AMV on northern China has become stronger since the mid-1990s.

There is also evidence that the recent negative phase of the Pacific Decadal Oscillation (PDO) is associated with changes over eastern Asia (Zhu et al. 2011). Therefore, variability in ocean SST appears of particular importance, as highlighted by Dong et al. (2016), which found that 76\% of the warming signal in model simulations is explained by SST/sea-ice extent changes, while $24 \%$ of the warming is due to increased concentration in greenhouse gases (GHG) and changes in anthropogenic aerosol emissions.

Other regional changes can also lead to changes of the atmospheric circulation over NEA. For example, Wu et al. (2010) showed that snow cover changes over the Tibetan Plateau contributed to recent changes over NEA by altering the contrast in temperature between the plateau and surrounding regions and, hence, leading to changes in sealevel pressure and winds. In addition Kwon et al. (2007) pointed out that a recent increased number of typhoons over Southern China has contributed to the upper-level circulation change through diabatic heating of the atmosphere. Precipitation has indeed changed following a shift to a dipole in precipitation anomalies: the South-Flood-North-Drought (SFND) pattern, which has emerged particularly strongly 
since the mid-90s (Kwon et al. 2007; Qian et al. 2014; Ueda et al. 2015; Han et al. 2015).

Among the aforementioned changes, potential predictability of the NEA's climate is underlined by (1) the change in external forcings (which are prescribed in near-term climate predictions), and (2) changes in SSTs via the remote atmospheric teleconnections. The main aim of this study is to assess the skill of state-of-the-art climate predictions over Asia, with a focus on the SAT and precipitation, and to understand the source of the predictive skill. The structure of the paper is summarized as follows: Sect. 2 describes the data used and the decadal prediction system. In Sect. 3 the skill in predicting surface-air temperature is presented and its source investigated. A discussion is given in Sect. 4 and a conclusion in Sect. 5.

\section{Data and method}

\subsection{DePreSys3}

We use the 3rd version of the UK Met Office Decadal Prediction System (DePreSys3; Dunstone et al. 2016). DePreSys3 is based on the Hadley Centre Global Environment Model version 3, global coupled configuration v2 (HadGEM3GC2; Williams et al. 2015). The atmosphere model is the Global Atmospheric version 6.0 of the Met Office Unified Model and is run at the $\mathrm{N} 216$ resolution $(\sim 60 \mathrm{~km}$ in midlatitudes) with 85 vertical levels ensuring a resolved stratosphere. The Ocean model is the Global Ocean version 5.0 (Megann et al. 2014), which is based on version 3.4 of the Nucleus for European Models of the Ocean model (NEMO; Madec 2008). The ocean is run at a quarter degree resolution using the NEMO tri-polar grid with 75 vertical levels (the ORCA025L75 grid; Bernard et al. 2006). The land surface model is version 6.0 Global Land version of the Joint UK Land Environment Simulator (JULES; Best et al. 2011) and the sea-ice models is CICE version 4.1 (Hunke and Lipscomb 2004) from the United States Los Alamos National Laboratory. These models are coupled with OASIS3 (Valcke 2013). More relevant details on the UM-JULES and NEMOCICE coupling are given in Walters et al. (2014) and Megann et al. (2014) respectively.

DePreSys 3 is full-field initialized by relaxing a coupled integration of HadGEM3-GC2 towards gridded observations. Ocean temperature and salinity are relaxed toward the Met Office global statistical ocean reanalysis (MOSORA; Smith and Murphy 2007; Smith et al. 2015) with a 10-day relaxation timescale. The sea-ice concentration is taken from HadISST sea-ice concentration (Rayner et al. 2003) with a one day relaxation timescale. The atmosphere model is initialized from and ERA-interim (Dee et al. 2011) atmospheric temperature and winds, using a 6-h relaxation timescale.
Hindcasts are forced by the historical evolution of external forcings (GHG, aerosols, ozone, solar, radiation and volcanoes) and follow RCP4.5 after 2005 as in the CMIP5 protocol (Taylor et al. 2012). Ten ensemble member hindcasts are started every 2-3 years between 1960 and 2008, and every year from 2009 to 2014 with a total of 26 start-dates (1960, 1962, 1965, 1968, 1970, 1972, 1975, 1978, 1980, 1982, 1985, 1988, 1990, 1992, 1995, 1998, 2000, 2002, 2005, 2008, 2009, 2010, 2011, 2012, 2013, 2014), covering the 1960-2014 period. Each hindcast lasts for 5 years. Members are initialized on the 1st November and the ten members are generated using different seeds to a stochastic physics scheme (MacLachlan et al. 2015).

\subsection{Observations/reanalysis}

To evaluate model skill we selected the National Centers for Environmental Prediction (NCEP) (R-2) reanalysis (hereafter referred to as NCEP), which is more accurate than the NCEP (R-1) reanalysis by the removing of several errors (Kanamitsu et al. 2002). This reanalysis offers a $2.5^{\circ}$ resolution (144 longitude grid points and 72 latitude grid points) with 17 altitude levels. The selected variables are air temperature, wind, specific humidity, geopotential height and surface air temperature ( $2 \mathrm{~m}$ up to the ground). NCEP spans a long-period (1948 to present) allowing the evaluation of the skill of using all DePreSys3 hindcasts.

For precipitation we used the Global Precipitation Climatology Center (GPCC) version v7 (Schneider et al. 2014), available from 1901 to 2013 on a $0.5^{\circ} \times 0.5^{\circ}$ longitude on a global grid $(720 \times 180)$. The full data product $\mathrm{v} 7$ is based on quality-controlled data from 67,200 stations world-wide.

\subsection{Bias adjustment}

Climate models do not perfectly simulate the observed climate. When initialized with observations, models drift toward their preferred imperfect climatology, which can lead to biases in the forecasts. Therefore, the drift has to be removed before assessing the ability of a prediction system to simulate climate. Here we used the standard procedure following the World Climate Research Program recommendations (ICPO 2011) to remove the drift, a posteriori and in a linear way: the $\operatorname{drift}(\operatorname{dr}(\tau))$ is computed as the difference between the average over all members $(i)$ and start-date $(j)$ of DePreSys $3\left(Y_{j}^{i}(\tau)\right)$, minus the corresponding observations/ reanalysis $\left(X_{j}(\tau)\right)$, for each lead-time $(\tau)$, i.e. $d r(\tau)=\frac{1}{n m} \sum_{j=1}^{n} \sum_{i=1}^{m} Y_{j}^{i}(\tau)-\frac{1}{n} \sum_{j=1}^{n} X_{j}(\tau)$ for $n$ start-dates and $m$ members.

The drift is thereby only dependent on the lead-time and we assume the drift to be independent of the start-date. Although some evidence highlights that the drift can be 
non-stationary and the result may be sensitive to this methodology (in the case where there is strong non-stationary drifts it could be preferable to use the method developed in Kruschke et al. 2016), we assume here the ICPO method to be a reliable bias adjustment method. The drift is then removed from the hindcasts at each lead-time. We estimate the drift in surface-air temperature, geopotential height and wind from NCEP, and in precipitation from GPCC. A mean surface air temperature bias, and the drift of SAT in several areas (global mean, subpolar gyre, North East Asia, North Atlantic) are shown in Figure S1.

\subsection{Evaluation of hindcast skill}

We evaluate the skill of DePreSys 3 to predict climate with the Anomaly Correlation Coefficient (ACC), r, given by

$$
r(\tau)=\frac{\sum_{j=1}^{n}\left[X_{j}(\tau) Y_{j}(\tau)\right]}{\sqrt{\sum_{j=1}^{n}\left[X_{j}(\tau)\right]^{2} \sum_{j=1}^{n}\left[Y_{j}(\tau)\right]^{2}}}
$$

where $Y_{j}$ is the ensemble mean anomaly for the $j$ th hindcast starting in year $j ; X_{j}$ is the observation anomaly for the corresponding starting date $j$. $\tau$ is the lead-time and $n$ the number of start dates. Anomalies for $X_{j}$ and $Y_{j}$ are calculated independently to have a zero mean over the hindcast period.

The significance of the ACC is estimated through resampling (5000 permutations) in a Monte Carlo framework. For each grid points, DePreSys3 times-series are randomly re-sampled and the correlations between DePreSys3 and NCEP are recalculated. Synthetic times-series are reconstructed using successive randomly selected 3 year periods until the size of the original time-series (the number of start dates) is reached, to preserve the multiannual variability. Obtained correlations follow a Gaussian distribution. Correlations are then judged significant at the $5 \%$ level when stronger than $97.5 \%$ of the randomly obtained correlation values. The persistence is computed using reanalysis from the years of and before the model initialization (on a 1 st of November). The $n$-year persistence is computed based on the observed values in the $n$ years prior to the start date. We computed a 1 year and a 4 year persistence.

\subsection{Wave activity flux}

The propagation features of the Rossby wave are analyzed by computing the wave activity flux, following the formulation by Takaya and Nakamura (2001):
$W=\frac{1}{2|\overline{\boldsymbol{u}}|}\left\{\begin{array}{l}\bar{u}\left(\psi_{x}^{\prime 2}-\psi^{\prime} \psi_{x x}^{\prime}\right)+\bar{v}\left(\psi_{x}^{\prime} \psi_{y}^{\prime}-\psi^{\prime} \psi_{x y}^{\prime}\right) \\ \bar{u}\left(\psi_{x}^{\prime} \psi_{y}^{\prime}-\psi^{\prime} \psi_{x y}^{\prime}\right)+\bar{v}\left(\psi_{y}^{\prime 2}-\psi^{\prime} \psi_{y y}^{\prime}\right)\end{array}\right\}$

where, $u$ is the zonal wind velocity, $v$ is the meridional wind velocity, subscripts $\mathrm{x}$ and $\mathrm{y}$ represent zonal and meridional gradients. $\boldsymbol{u}$ is the horizontal wind velocity: $\mathbf{u}=(\mathrm{u}, \mathrm{v}) . \Psi$ represents eddy stream functions. Overbars represent the climatology and primes the perturbation (deviation from the climatology). The wave activity flux is computed with monthly fields.

\section{Results}

\subsection{Skill in predicting surface-air temperature}

First we assess the prediction system ability to predict SAT by computing the ACC from DePreSys 3 and NCEP for the first year and the 2-5 year lead-time. The skill of the first year represents the seasonal-to-interannual predictions; the 2-5 year lead-time represents the interannual timescale (Goddard et al. 2013). In summer (JJAS), the ACC for DePreSys3 is high over the equatorial and subtropical Atlantic Ocean, the Pacific Ocean, Indian Ocean and over Eastern Europe, the Arabian Peninsula and northern China and Mongolia (Fig. 1a). The ACC is larger for the 2-5 year lead-time, especially over the North Atlantic Ocean (subpolar gyre), the Mediterranean Sea and surroundings regions, and over Russia (Fig. 1b). The larger ACC for the 2-5 year lead time, compared to the 1 year lead time, is likely due to the temporal smoothing (4-year average) and to the long term trend induced by external forcing (Goddard et al. 2013).

van Oldenborgh et al. (2012) have shown that skill in predicting SAT is primarily determined by the response to external forcings. Since the main aim of a decadal prediction system is to provide information to decision makers on short-term time horizon, a particular focus is made on the skill at capturing changes relative to the long-term trend. We thus removed the long term trend by subtracting a linear trend from both hindcasts and observations/ reanalysis. A linear trend may not be the best estimate of the impact of increased GHG on climate, hence leading to uncertainties in assessing the skill in predicting temperature in regard to the long-term trend. We thus also calculated skill in predicting SAT after regression between surface air temperature and the radiative forcing of GHG (in $\mathrm{CO}_{2}$ equivalent), following van Oldenborgh et al. (2012). However, we found very similar results in predicting SAT (Fig. S2) because the radiative forcing due to GHG emissions was approximately linear over the 

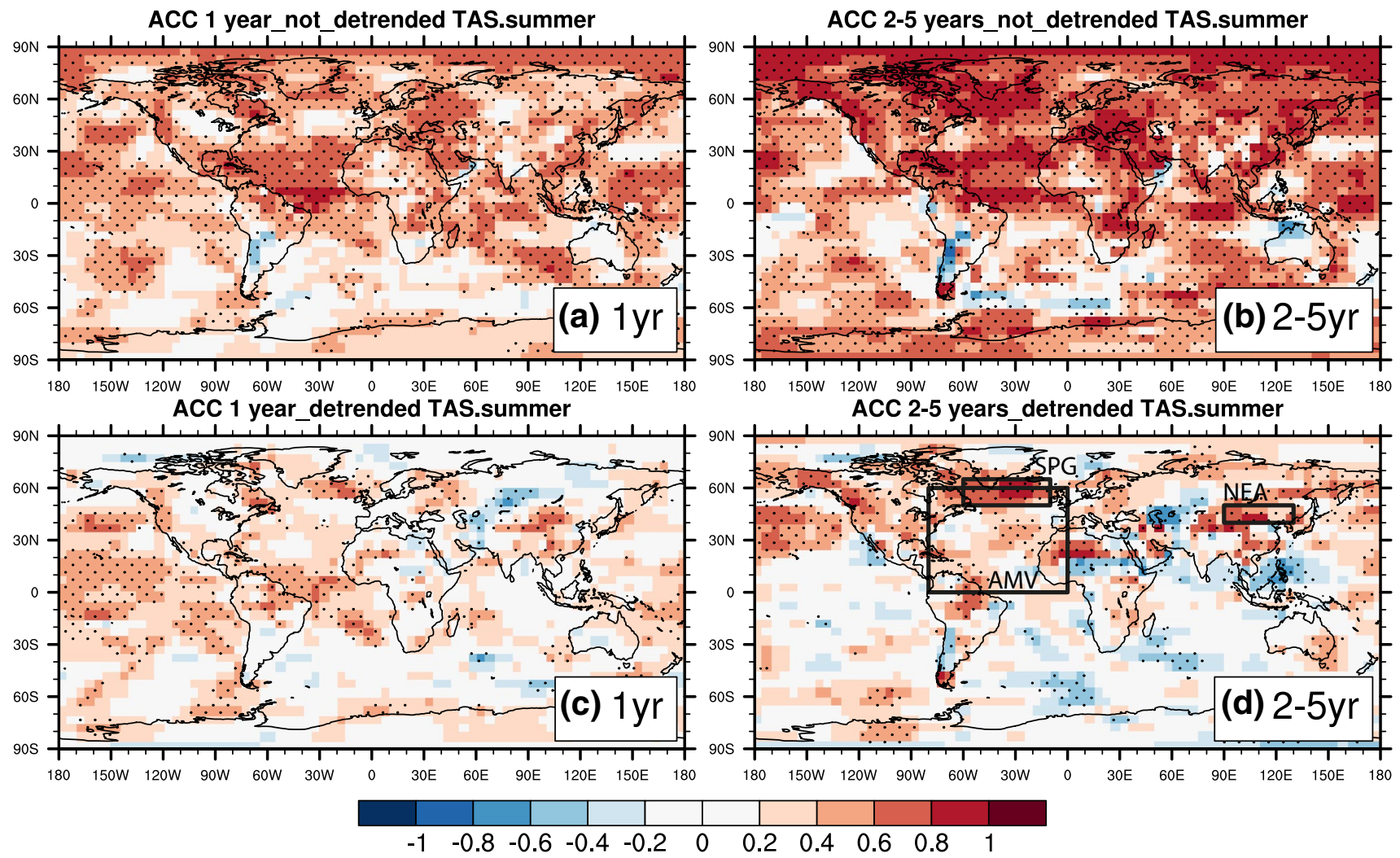

Fig. 1 Anomaly correlation coefficient skill score (ACC) for SAT in DePreSys3 hindcasts (using NCEP as observations) in summer (JJAS) for a year 1, b year 2-5 lead-times. Also shown is the ACC calculated after a linear trend is removed at each grid-point for $\mathbf{c}$ year
1 and $\mathbf{d}$ year 2-5. Stippling indicates that the ACC is different to zero at the $95 \%$ confidence level according to a Monte-Carlo procedure (see text for details)

predictability of the Atlantic Ocean owing to the memory of the ocean, including the inertia of the AMOC (Pohlmann et al. 2004, 2013). Indeed, the skill in predicting the evolution of the subpolar gyre has been linked to the ocean initialization (Yeager et al. 2012; Robson et al. 2012; Msadek et al. 2014; Monerie et al. 2017).

We now focus the analysis of skill for SAT averaged over four regions defined on the Fig. 1d: the subpolar gyre [SPG; $50^{\circ} \mathrm{N}-65^{\circ} \mathrm{N} ; 60^{\circ} \mathrm{W}-10^{\circ} \mathrm{W}$; as defined in Robson et al. (2012)], the Atlantic Multidecadal Variability [AMV; $0^{\circ} \mathrm{N}-60^{\circ} \mathrm{N} ; 80^{\circ} \mathrm{E}-0^{\circ} \mathrm{W}$, as defined in Trenberth and Shea (2006)], NEA $\left[40^{\circ} \mathrm{N}-50^{\circ} \mathrm{N} ; 90^{\circ} \mathrm{E}-130^{\circ} \mathrm{E}\right.$; as defined in Chen and $\mathrm{Lu}$ (2014)] and we add the global mean surface temperature (GMST; $\left.90^{\circ} \mathrm{S}-90^{\circ} \mathrm{N} ; 180^{\circ} \mathrm{W}-180^{\circ} \mathrm{E}\right)$. Results are presented in Fig. 2. When including trends, the skill in predicting GMST is high for GMST for both DePreSys3 and the persistence ( $>0.9$, see Fig. $2 a)$. When the trend is removed the ACC for DePreSys3 is reduced to $\sim 0.5$, but remains larger than for the persistence (except for the first summer). Thus, the prediction system is able to retrospectively predict GMST, giving confidence that DePreSys 3 can broadly simulate and predict climate variability.
The high values of ACC for predictions of SAT over the subpolar gyre is consistent with the high potential 
Fig. 2 Anomaly correlation coefficient (ACC) for SAT in DePreSys 3 hindcasts (using NCEP as observations) in summer (JJAS) for a the global mean surface temperature $\left(90^{\circ} \mathrm{S}-90^{\circ} \mathrm{N} ; 180^{\circ} \mathrm{W}-180^{\circ} \mathrm{E}\right), \mathbf{b}$ the subpolar gyre $\left(50^{\circ} \mathrm{N}-65^{\circ} \mathrm{N}\right.$; $\left.60^{\circ} \mathrm{W}-10^{\circ} \mathrm{W}\right), \mathbf{c}$ the Atlantic Multidecadal Variability $\left(0^{\circ} \mathrm{N}-60^{\circ} \mathrm{N} ; 80^{\circ} \mathrm{E}-0^{\circ} \mathrm{W}\right)$ and $\mathbf{d}$ North East Asia $\left(40^{\circ} \mathrm{N}-50^{\circ} \mathrm{N}\right.$; $\left.90^{\circ} \mathrm{E}-130^{\circ} \mathrm{E}\right)$, for different lead-times (the first summer, $2-3,3-4,4-5$ and 2-5 year). The red (black) line represents the skill score of DePreSys3 (persistence). The dashed (continuous) line is used for linearly detrended values (raw values). A red circle indicates that the ACC is significantly different to zero at the $95 \%$ confidence level according to a Monte-Carlo procedure (see text), and larger than the corresponding ACC for persistence
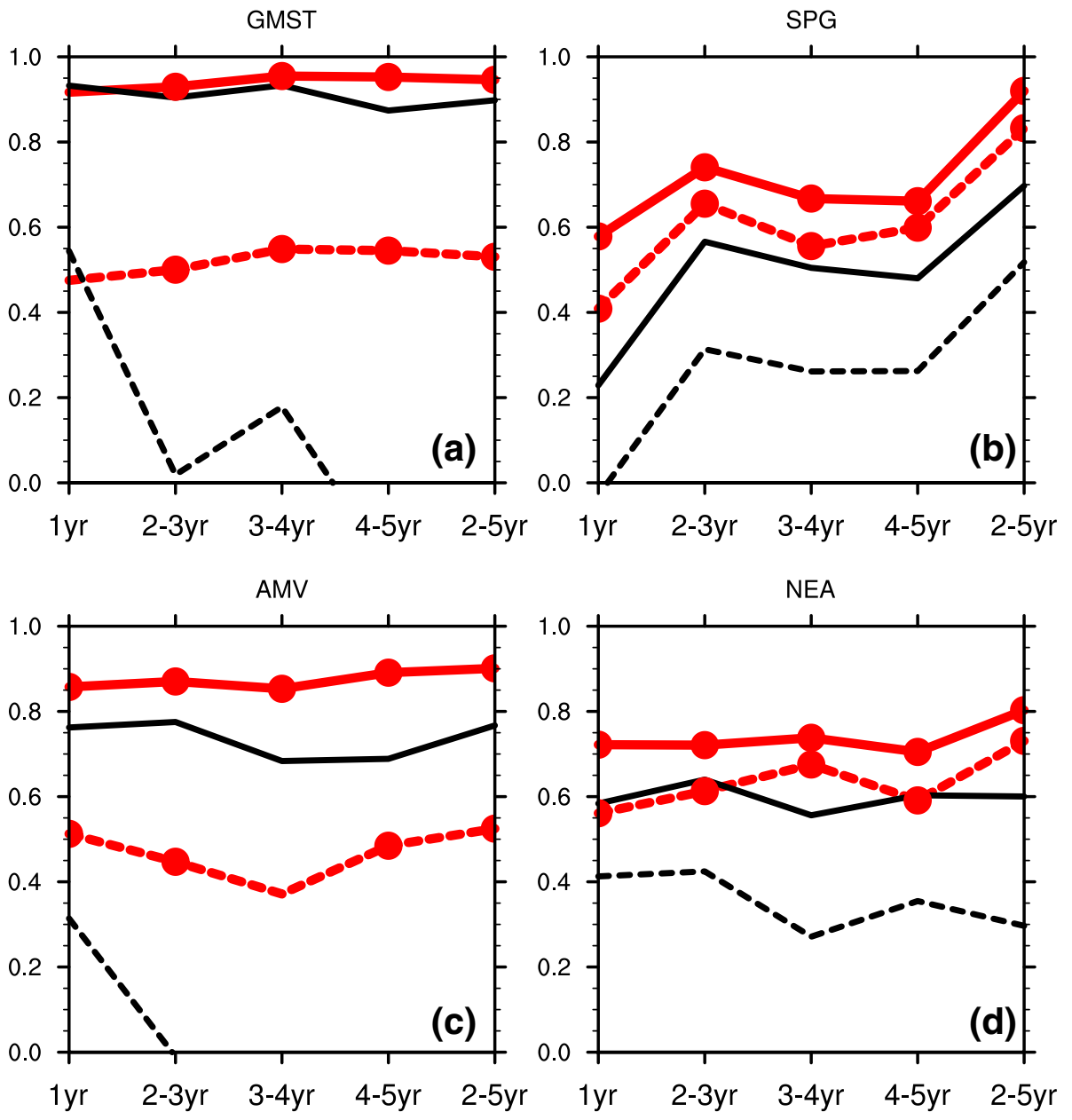

For the SPG, the ACC for DePreSys3 is significant for all lead-times when the linear trend is removed (Fig. 2b). This is consistent with Menary et al. (2016) that found skill in predicting the top $500 \mathrm{~m}$ Labrador Sea temperature in DePreSys3. The skill is particularly high for the 2-5 year lead time, when the time-series are smoothed. Removing the trend does not drastically alter the ability of DePreSys3 to predict SAT over the SPG since the longterm warming is weak.

Although there is substantial skill at capturing the AMV (ACC $>0.8$ ), the skill reduces to $\sim 0.5$ after detrending (Fig. 2c). The relatively low skill in predicting the AMV contrasts somewhat with the high skill in predicting detrended SAT variability over the subpolar gyre. However, it is consistent with the result of the Fig. 1d, e.g. stronger values of the ACC are found over the north Atlantic than over the equatorial and subtropical Atlantic Ocean (excepted for the 1 year lead-time).

Over NEA the skill is high ( $>0.6$ and significant) for all the lead times (Fig. 2d). The skill in predicting the temperature over NEA is not mainly due to a long-term warming since the detrended values are almost as strong as the non-detrended ones.

While the ACC skill score measures only the phase difference between observations and hindcasts, the root-mean square error (RMSE) measures the magnitude of the error between hindcasts and observations. Therefore, these metrics provide complementary information on the prediction skill of DePreSys3. RMSE also shows that DePreSys3 provides better skill than the persistence, and that skill in 
predicting SAT over the SPG and NEA is improved for the 2-5 year lead-time. Over both NEA and the SPG the RMSE is smaller when the trend is removed (Fig. S4).

Similar levels of skill in predicting the AMV, SPG and NEA indices do not imply by itself a relationship between North Atlantic and NEA. However, the SAT has undergone a similar multidecadal evolution in each of these regions, with a cooling over the 1960s and a warming during the 1990s, which has shown by numerous authors for the AMV (Martin and Thorncroft 2014; among others), the SPG (Robson et al. 2012) and NEA (Zhao et al. 2014; Chen and Lu 2014; Gao et al. 2014; Dong et al. 2016) (see also Fig. S5ac). Hence, the similarity between detrended SAT in Asia and over the North Atlantic is assessed in the Sect. 3.2.

\subsection{Evolution of surface-air temperature over the subpolar gyre, North East Asia and the Atlantic multidecadal variability}

We assess the ability of DePresys 3 to simulate the low and high frequency SAT variability for the 1 st year lead-time (Fig. 3) and the 2-5 year lead-time (Fig. 4).

Figure 3 shows that the SAT evolution over the SPG, the AMV and NEA for summer (JJAS). Note that NCEP is included between the lower and upper bounds of the DePreSys3 inter-ensemble standard deviation which further suggests that DePreSys3 is able to simulate the observed climate variability in these regions (Fig. 3a-c, 1-year lead-time). We decompose the time-series of 1 year lead-time predictions into low frequency (by using a 5-year running mean) and high frequency components (defined as the residual departure from the low-frequency component).

For the SPG and the 1 year lead-time, the multidecadal evolution of the low frequency component is well simulated $(r=0.84)$ (Fig. 3d). Over the subpolar gyre the temperature decreased during the 1960s and experienced an abrupt warming during the mid-1990s in observations (Fig. 3a) (Robson et al. 2012, 2014). DePreSys3 is able to reproduce this multidecadal SAT variability. The low-frequency component of the NEA index is also well simulated $(\mathrm{r}=0.90)$ (Fig. 3f) and resembles the evolution of the SPG index (Fig. 3d). The low-frequency of the AMV index is also well simulated $(\mathrm{r}=0.65)$. However, DePreSys 3 appears to simulate the AMV index with a slight delay in phase in comparison with NCEP (the weakest values occurred in the mid-90s in NCEP and in the mid-1980s in DePreSys3). The delay in phase is not obtained when analyzing the whole time-series (Fig. S5), and is due removal of the trend from the time-series with the poor sampling (one start-date every 2-3 years), which highlights the cooling of the early 1990 s in NCEP more strongly.

In contrast the decomposition shows that the weak correlation for the 1 year lead-time SPG index overall is due to the inability of DePreSys 3 to predict the high-frequency component of the SPG variability (Fig. 3g). Note that we are dealing with SAT which is noisier than oceanic heat content as it is more easily impacted by surface winds. The skill in predicting the subpolar gyre could be higher using heat content (Chikamoto et al. 2013) as found by Menary et al. (2016) with DePreSys3. For NEA the high frequency index is noisier and less predictable than the low-frequency component of the SAT evolution (Fig. 3i). The AMV index does exhibit a good correlation for high frequency component $(\mathrm{r}=0.64)$ (Fig. 3h).

Time series showing the $2-5$ year anomalies are shown in Fig. 4. Correlations are strong and significant for the SPG, the AMV and NEA indices $(0.82,0.52$ and 0.73 respectively). The mid-1990s shift is also reproduced for both SPG and NEA indices, but with a weaker intensity in DePreSys3 (Fig. 4a, c).

Interestingly the low frequency temperature evolution over NEA resembles the temperature evolution over the North Atlantic, with a decrease in temperature over the 1960s and a strong warming over the 1990s (Fig. 3c). The latter is consistent with the rapid warming which occurred there during the mid-1990s (Chen and Lu 2014). We do not obtain a strong warming over NEA for the other seasons (not shown), in consistency with Gao et al. (2014), which have shown that the "shift" was stronger in summer than in winter. In both observations and DePreSys3, the SAT evolution over the North Atlantic (SPG and AMV) is similar to the evolution of the SAT over the NEA box.

As there are uncertainties in observational reanalysis we have also used several other observed datasets of near-surface air temperature (CWT, Cowtan and Way 2014; BEST; Rohde et al. 2013; GISTEMP; Hansen et al. 2010; MLOST; Vose et al. 2012). Results indicate that different data sets give very similar time evolutions of SAT indices over SPG, AMV and NEA (Fig. S5). The skill of DePreSys3 to accurately simulate the low-frequency SAT variability over these three regions is thus robust and not sensitive to a particular observational data set used for model evaluation.

Since we found strong similarities between SAT variability over NEA and the North Atlantic we assess whether DePreSys 3 simulates a link between these areas in the next section.

\subsection{Changes in the atmospheric circulation associated with the mid-90s North-east Asian warming}

We now explore the mechanism associated with the abrupt summer (JJAS) warming that occurred over the SPG and NEA by computing the difference between two periods: 1995-2010 minus 1979-1994, i.e. the years before and the years after the mid-1990s warming (as seen in Fig. 4d with the blue vertical lines). We used the low-frequency 

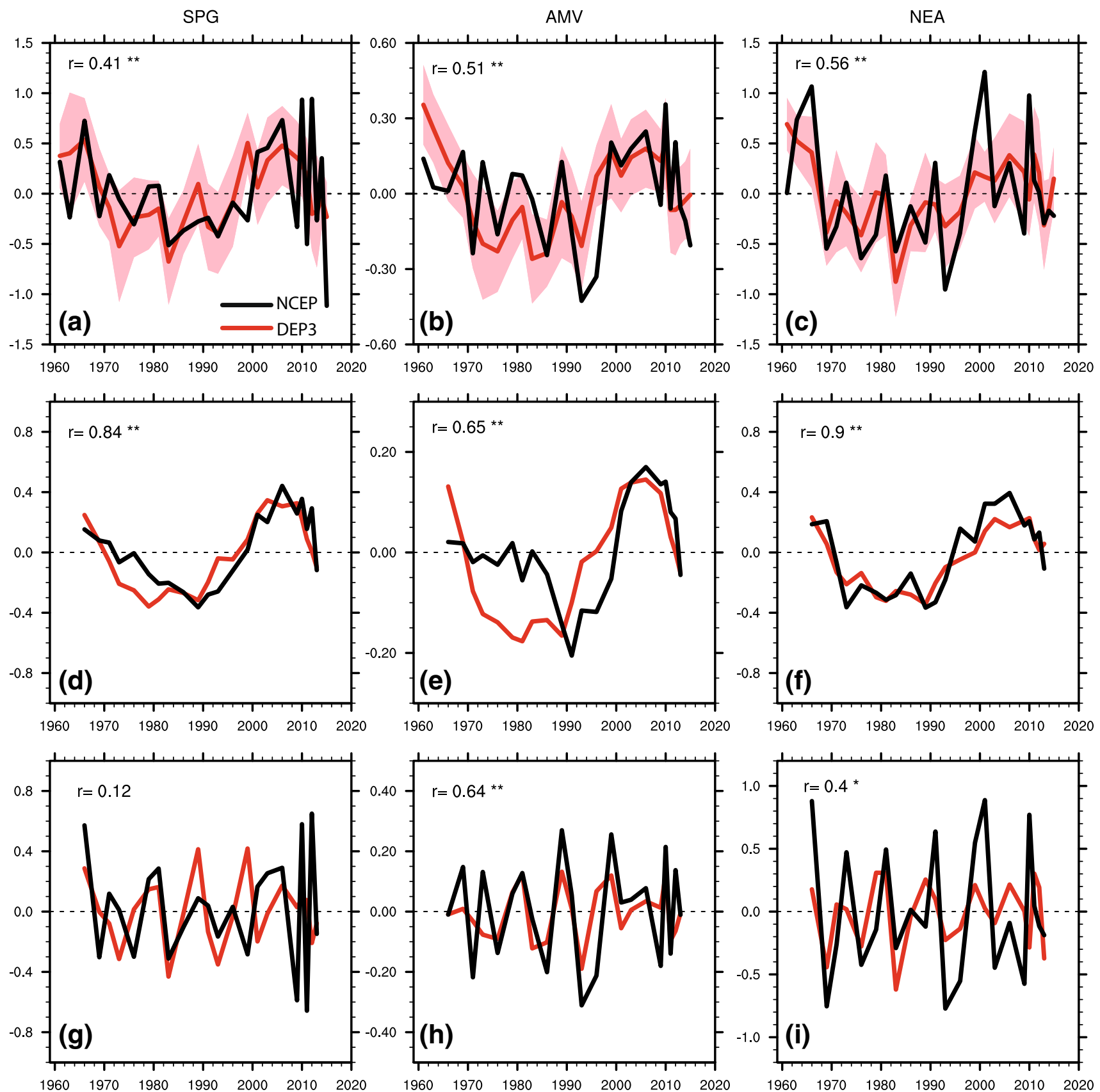

Fig. 3 Summer (JJAS) SAT evolution of NCEP (black line) and DePreSys 3 ensemble-means (red line) for the 1 year lead-time (first row), the low-frequency part of the SAT evolution (i.e. with a 5 year running mean-middle row) and the high-frequency part of evolution of the SAT (top minus middle row; bottom row), for the SPG (left column), the AMV (middle column) and NEA (right column). The spread is computed on the ten members as more or less 1 standard deviation (red shading). All time-series have been linearly detrended. The correlation between NCEP and DePreSys3 time-series is shown in the top left of each panel. The significance of the correlation has been assessed through a Monte Carlo framework. One star indicates that the correlation is significant at the $90 \%$ confidence level. Two stars indicate that the correlation is significant at the $95 \%$ confidence level

over the Northern Hemisphere than in NCEP (Fig. S6). Therefore, to highlight the modulation of SAT over land in DePreSys3 and in NCEP, we remove a spatial-average over the plotting region of temperature at each grid-point in Fig. 5 (see Sects. 3.3.1 and 3.3.2). For consistency a spatial-average 

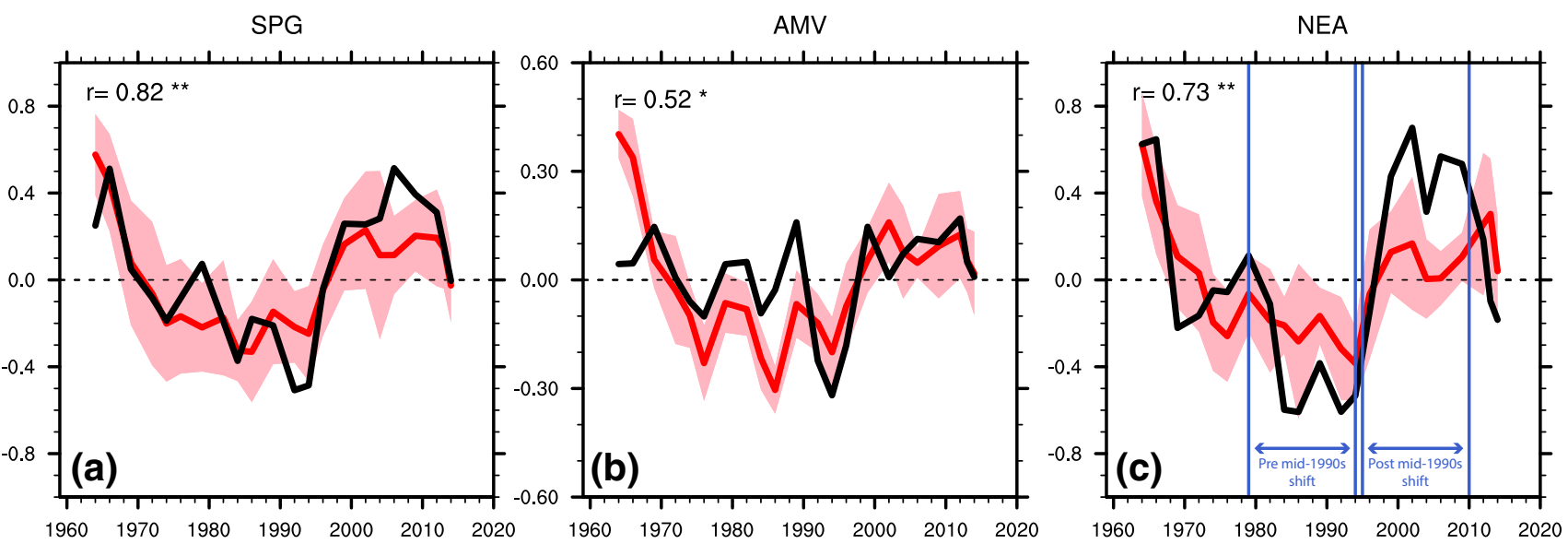

Fig. 4 As for the Fig. 3a-c but for the 2-5 year lead-time

over the same plotting region was also removed for the sealevel pressure and the low-level streamfunctions. For geopotential height we removed a zonal mean to highlight gradients associated with circulation change.

\subsubsection{Impact of the observed circumglobal teleconnection pattern}

At both the 1 year and 2-5 year lead-times, NCEP shows a significant increase in SAT over NEA, North Russia, West of the Pacific Ocean, the Northern Atlantic Ocean and Northern Europe, Western North America and Alaska (Fig. 5a). The Pacific Ocean exhibits a shift to a negative phase of the Interdecadal Pacific Oscillation, as indicated by the cooling over the eastern Pacific Ocean and the warming over the subtropical north and South Pacific Ocean. There is a dipole over north Africa with a warming over the Saharan desert and a cooling over the Sahel, denoting a northward shift of the monsoon cell and an increase in Sahel precipitation, i.e. the Sahel precipitation recovery (Nicholson 2013; Sanogo et al. 2015). The warming is stronger over the North Atlantic Ocean and NEA at the 2-5 year lead-time (Fig. 5b).

In NCEP the composite analysis exhibits a modulation of SAT with zonally distributed successive patterns of positive/negative anomalies, which seem to be associated with atmospheric circulation changes related to a large-scale process: the circumglobal teleconnection pattern (CGT) (Ding and Wang 2005). Indeed these positive and negatives SAT anomalies are associated with an increase (over the western part of the Northern Atlantic Ocean, the over subtropical Atlantic Ocean, Northern Europe and NEA) and a decrease (over the eastern North Atlantic Ocean, central Eurasia and North West America) in $250 \mathrm{hPa}$ geopotential height (ZG250), successively (Fig. 6a, b). The Rossby wave propagates along the subtropical westerly jet (blue lines), which acts as a wave-guide, as indicated by the wave activity flux (red arrows). The wave path is different for the 1 year leadtime than for the 2-5 year lead-time. For the first year leadtime, the observed wave propagates over northern Russia and moves then southward to reach eastern Asia and Japan by following the polar front, propagating from $90^{\circ} \mathrm{E}$ and $80^{\circ} \mathrm{N}$ to $110^{\circ} \mathrm{E}$ to $45^{\circ} \mathrm{N}$ (Fig. 6a). For the $2-5$ year lead-time the wave propagates more southward, staying south of $70^{\circ} \mathrm{N}$.

Changes in the high level atmosphere projects to the surface since observed changes in Sea Level Pressure (SLP) highlight the eastward progression of a Rossby wave: SLP decreases over the Sahel and the northern subtropical Atlantic Ocean, Western Europe, over East Asia and Siberia for both the 1 year and the $2-5$ year lead-times (Fig. 7a, b). A decrease in SLP is associated with negative values in stream function and thus with cyclonic circulation anomalies. An increase in SLP is associated with positive values in stream function and thus with an anomalously anticyclonic circulation at the surface. Over East Asia SLP decreases and there is a cyclonic circulation. Over NEA, the increase in SAT is located eastward of the decrease in SLP and of the lowlevel cyclonic circulation. Thus, the southerlies appear to contribute to the SAT warming, by advecting heat from the South and East of NEA.

The geopotential height anomalies are also analyzed at 500 and $850 \mathrm{hPa}$. The results reveal barotropic anomalies over the North Atlantic Ocean and Europe, and baroclinic anomalies over Asia and the subtropical Atlantic Ocean (Fig. S7). The baroclinic structure over NEA is also shown by the cyclonic anomaly obtained at low-level (Fig. 7a, b) and the anticyclonic anomaly obtained at upper-level (Fig. 6a, b). Change in the low-level atmosphere circulation does not directly follow the changes obtained at upper-level. This is likely due to the strong surface warming (Fig. 5) that induces a decrease in SLP and is associated with cyclonic circulation anomalies (Fig. 7). 
Fig. 5 The difference in temperature $\left({ }^{\circ} \mathrm{C}\right)$ in summer (JJAS) between the 1995-2010 minus the 1979-1994 periods for lead time 1 year and 2-5 years, for both NCEP $(\mathbf{a}, \mathbf{b})$ and DePreSys3 (c, d). We removed a spatial temperature average (from $20^{\circ} \mathrm{S}$ to $90^{\circ} \mathrm{N}$ and $180^{\circ} \mathrm{E}$ to $180^{\circ} \mathrm{E}$ ) to highlight changes occurring over land in DePreSys3. All grid-points were linearly detrended before the composite was computed. North East Asia (NEA) is defined as the box represented in black: $\left(90^{\circ} \mathrm{E}-130^{\circ} \mathrm{E} ; 40^{\circ} \mathrm{N}-50^{\circ} \mathrm{N}\right)$. Dots indicate that anomalies are significant at the $95 \%$ confidence level according to a Student's t-test. Note the different colour bars for NCEP $(\mathbf{a}, \mathbf{b})$ and DePreSys3 (c, d)
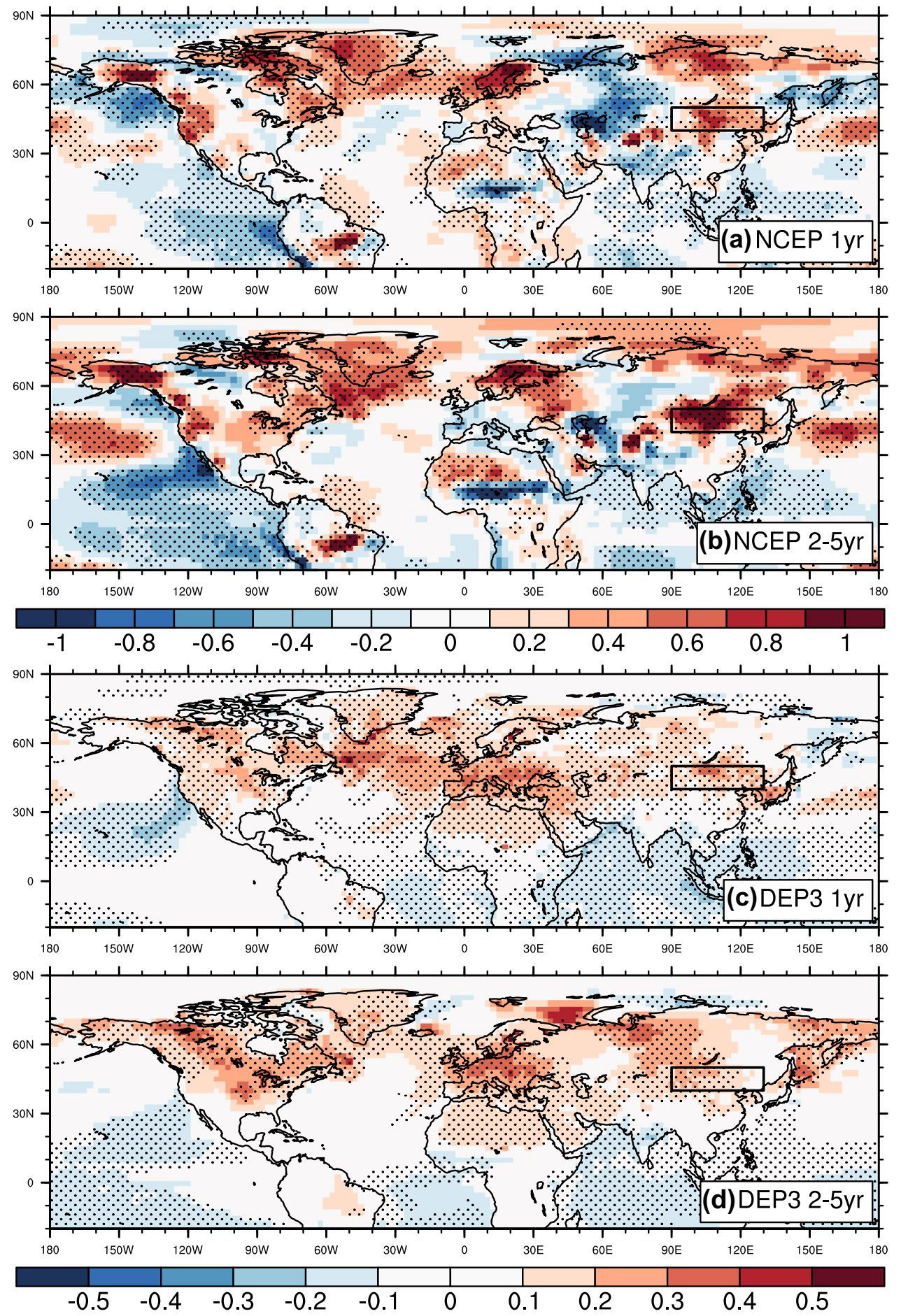

The results obtained above that show that Asia's climate was modulated by a wave pattern is consistent with a growing body of evidence that highlights the importance of Rossby waves on this area ( $\mathrm{Lu}$ et al. 2002; Enomoto et al. 2003; Enomoto 2004; Ding et al. 2011; Kosaka et al.
2011; Huang et al. 2012; Wu et al. 2016a, b; Lin et al. 2016; Wang et al. 2017). The associated pattern is known as "silk road" or CGT pattern, depending on the path of the wave. 
Fig. 6 As in the Fig. 5 but for the geopotential height anomalies at $250 \mathrm{hPa}(\mathrm{m}$; colors) and the wave activity fluxes $\left(\mathrm{m}^{2} \mathrm{~s}^{-2}\right.$ vectors). The zonal mean was removed to highlight gradients in geopotential heights. North East Asia (NEA) is defined as the box represented in black: $\left(90^{\circ} \mathrm{E}-130^{\circ} \mathrm{E} ; 40^{\circ} \mathrm{N}-50^{\circ} \mathrm{N}\right)$. Dots indicate that anomalies of geopotential height are significant at the $95 \%$ confidence level according to a Student's t-test. Note the different colour bars for NCEP (a, b) and DePreSys3 $(\mathbf{c}, \mathbf{d})$
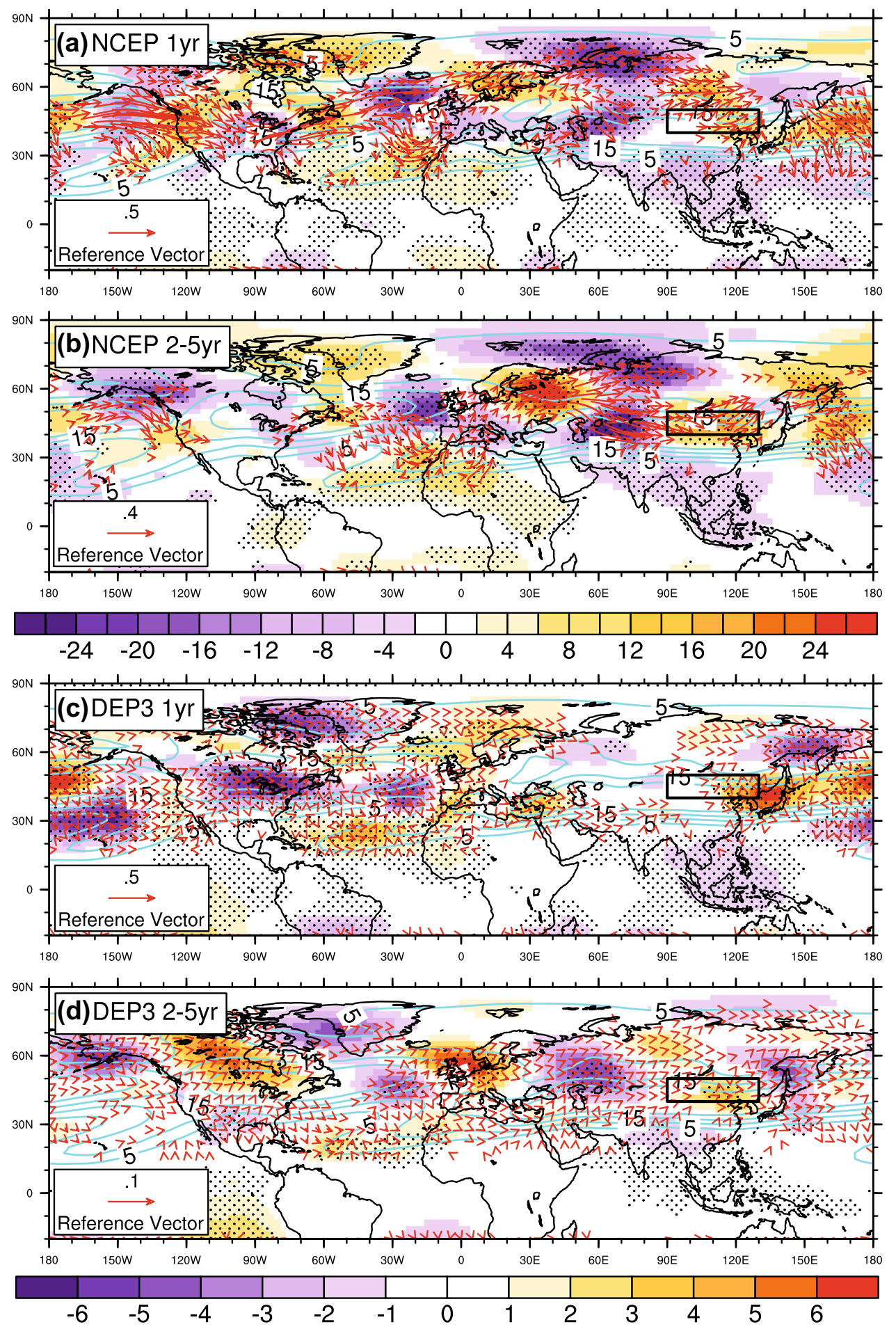

\subsubsection{Impact of the simulated circumglobal teleconnection pattern}

At a 2-5 year lead-time DePreSys3 exhibits a wave pattern, which is associated with a significant warming over Western Europe, from central Russia to East Asia (from $70^{\circ} \mathrm{E}$ to $120^{\circ} \mathrm{E}$, center around $50^{\circ} \mathrm{N}$ ) and North of Japan (from $150^{\circ} \mathrm{E}$ to $180^{\circ} \mathrm{E}$ ) (Fig. 5d). In comparison, temperature over Western Russia (from $40^{\circ} \mathrm{E}$ to $60^{\circ} \mathrm{E}$ ) and Eastern Russia (from $120^{\circ} \mathrm{E}$ to $150^{\circ} \mathrm{E}$ ) warmed less. Similar to the observed changes, regions of weak change in SAT are associated with negative anomalies in ZG250 and regions with a strong surface warming are associated with positive anomalies of ZG250 (Fig. 6d). The wave activity flux indicates 
Fig. 7 As in the Fig. 5 but for the sea-level pressure anomalies (hPa; colors) and low-level streamfunction (in $10^{6} \mathrm{~m}^{2} \mathrm{~s}^{-1}$; red continuous contours for positive values; blue discontinuous contours for negative values; black contours for the zero value). For NCEP contours are displayed every $0.20 \times 10^{6} \mathrm{~m}^{2} \mathrm{~s}^{-1}$; For DePreSys 3 contours are displayed every $0.02 \times 10^{6} \mathrm{~m}^{2} \mathrm{~s}^{-1}$. We removed a spatial temperature average (from $20^{\circ} \mathrm{S}$ to $90^{\circ} \mathrm{N}$ and $180^{\circ} \mathrm{E}$ to $180^{\circ} \mathrm{E}$ ). North East Asia (NEA) is defined as the box represented in red: $\left(90^{\circ} \mathrm{E}-130^{\circ} \mathrm{E} ; 40^{\circ} \mathrm{N}-50^{\circ} \mathrm{N}\right)$. Dots indicate that anomalies of sea-level pressure are significant at the $95 \%$ confidence level according to a Student t-test. Note the different colour bars for NCEP (a, b) and DePreSys3 (c, d)
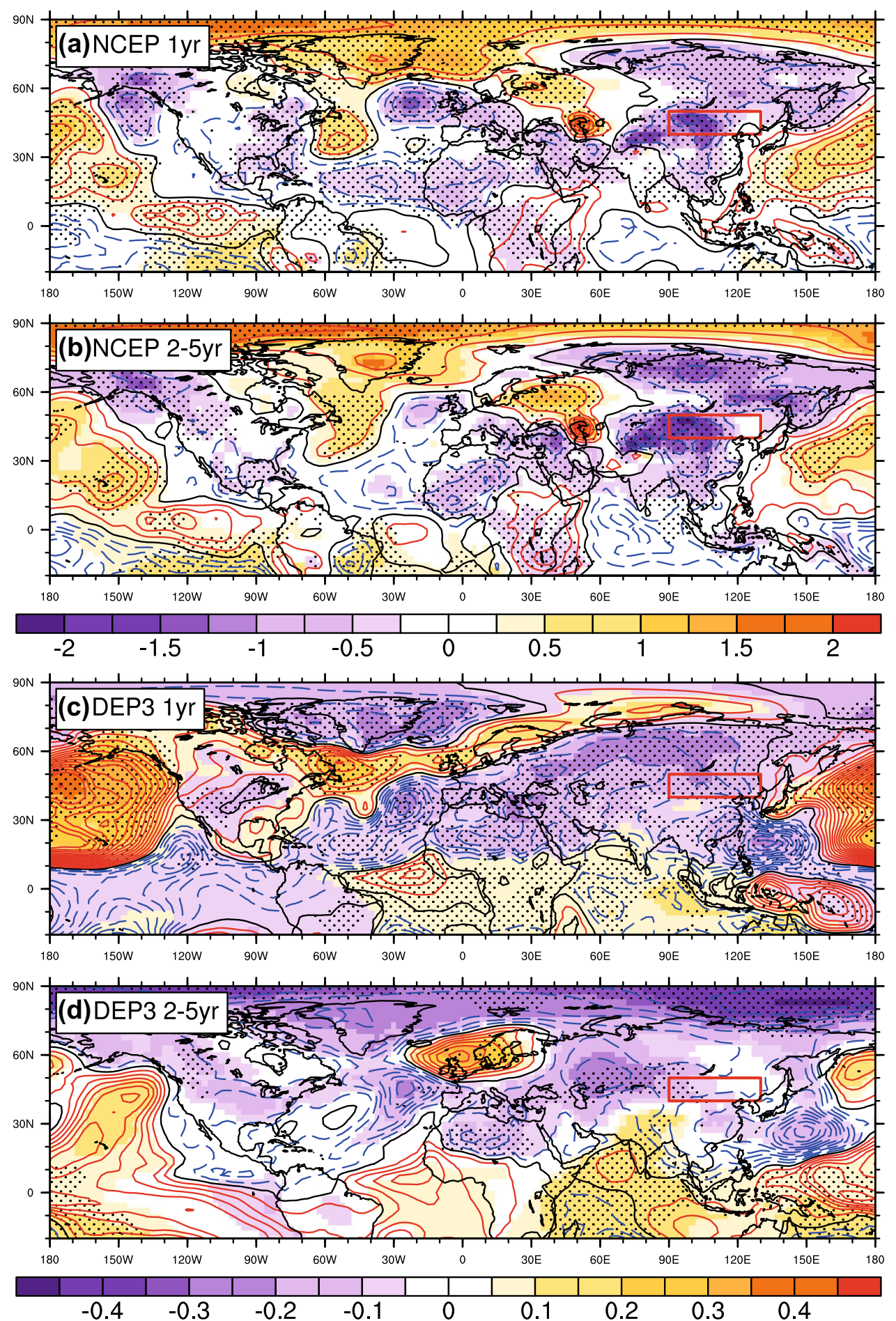

that a Rossby wave propagates from the Atlantic Ocean to East Asia, following the subtropical westerly jet. As for the NCEP, anomalies in ZG250 in DePreSys3 weaken as the wave propagates to the East (i.e. ZG250 changes are stronger over Europe than over East Asia).

Along with the changes in the upper atmosphere, SLP decreases from the subtropical Atlantic Ocean to eastern Asia and increases over northern Europe (Fig. 7d). As for NCEP the SLP decrease is associated with a negative anomaly in stream function over East Asia and over the western subtropical Pacific Ocean, indicating cyclonic circulation anomalies at low-level. These anomalies over the western subtropical Pacific Ocean are in-line with the negative anomalies of ZG250 at the upper-level, hence, they are exhibiting a barotropic structure. Over Asia the large extension of negative SLP anomalies is associated with the 
strong warming over land and reveals a complex relationship between changes occurring at the surface and throughout the atmospheric column, which leads to a baroclinic structure over East Asia.

At the 2-5 year lead-time the composite analysis reveals strong resemblances between NCEP and DePreSys3, despite a slight phase shift in ZG250 anomalies, highlighting the importance of an accurate simulation of atmospheric teleconnections to predict temperature over land. However, note that SAT and atmospheric changes are weaker in DePreSys3 than in NCEP, which is likely due to the average over ten members with a large internal variability. For instance changes in upper-level geopotential height is five times stronger in NCEP than in DePreSys3 (Fig. 6).

Although there are strong evidences for a CGT pattern at the 2-5 year timescales the first year lead-time ZG250 anomalies do not clearly indicate a CGT pattern since there is no obvious eastward propagation between $40^{\circ} \mathrm{E}$ and $100^{\circ} \mathrm{E}$ in the northern Hemisphere (Fig. 6c). However, the wave activity flux indicates that the wave propagates more southward, following the southern boundary of the subtropical westerly jet, as in the "silk Road" pattern of Enomoto et al. (2003). As in Enomoto et al. (2003) the ZG250 anomalies are found over the Eastern Mediterranean Sea (negative anomaly) and northeast (negative anomaly) and west (positive anomaly) of northern India. The ZG250 change over East Asia is also associated with changes occurring over the North Pacific Ocean where the south-to-north zonal anomalies are similar to the Pacific-Japan (PJ) pattern (Nitta 1987), which is known to impact eastern Asia and Japan (Wu et al. 2016b). The PJ pattern has been associated with SSTs over the Pacific Ocean during the preceding winter (Kosaka et al. 2012). DePreSys3 is able to predict SAT over the Pacific Ocean in winter for the 1 year lead-time (Figs. S8 and S9), the Pacific Ocean could thus, also, be a source of predictability for East Asia. However, Kosaka and Nakamura (2010) have shown that the PJ pattern is better defined at low than at high level while it is not the case with DePreSys3 (Fig. S7) revealing that such a teleconnection is not clear here.

Interestingly DePreSys 3 exhibits high skill in predicting SAT over the SPG, Eastern Europe, NEA and the Northwestern Pacific, for the 2-5 year lead-time (Fig. 1d) where we found positive anomalies of ZG250 in both NCEP and DePreSys3 (Fig. 6). Thus, prediction of the SAT changes over these areas appears be related to the ability of DePreSys 3 to simulate a large-scale atmospheric teleconnection pattern that links these regional SAT changes to remote SST anomalies. The mechanism involving a Rossby wave to modulate the change in temperature over NEA is consistent with Lin et al. (2016) and (Wu et al. 2016a, b) which have highlighted the impact of the interdecadal circumglobal teleconnection pattern (CGT) over Eastern Asia. However, the source of the wave has still to be defined.

\subsection{The origin of the circumglobal teleconnection}

Rossby waves that impact eastern China have been associated with changes over the (1) Atlantic Ocean (Wu et al. 2016a, b; Lin et al. 2016; Wang et al. 2017), (2) the Pacific Ocean (Ding et al. 2011; Lin et al. 2016) and (3) the Indian summer monsoon (Enomoto et al. 2003). Diabatic heating due to increased precipitation over these areas can lead to disturbances at upper-level and to a propagation of energy via a Rossby wave (Hoskins et al. 1977; Hoskins and Karoly 1981; Lau 1997). However, in DePreSys3 we cannot propose a role of the Indian monsoon since we do not see changes in precipitation for both the 1 year and the $2-5$ year lead-time (Fig. 8c, d). Moreover skill in predicting summer Indian precipitation is not significant (Fig. S10). The PJ pattern is not well defined for the 1 year lead-time and DePreSys 3 does not exhibit skill in predicting SAT over the Pacific Ocean for the 2-5 year lead-time. In addition the simulated and observed wave activity fluxes do not clearly show a wave propagation from the Pacific Ocean to East Asia (Fig. 6). Therefore, we focus on changes over the Atlantic Ocean.

In DePresys 3 positive anomalies of precipitation over the northern subtropical Atlantic and negative anomalies of precipitation over the southern subtropical Atlantic (Fig. 8c, d) are indicative of a northward shift of the ITCZ [which is also clearly seen in GPCP (Fig. S11), albeit using a shorter period]. The Sahel precipitation recovery is also evident in GPCC (Fig. 8a, b) and DePreSys3 (Fig. 8c, d). This northward shift in the ITCZ is consistent with Sheen et al. (2017), who highlighted the skill of DePreSys 3 to predict Sahel precipitation mainly due to the ability of DePreSys3 to simulate the AMV. Indeed, the AMV is known to strongly impact Sahel precipitation (Knight et al. 2006; Martin and Thorncroft 2014). The strengthening of the ITCZ over the subtropical Atlantic is also associated with a precipitation decrease over the northern Brazil and South America (an area which also shows high skill for precipitation in summer-Fig. S10).

The ability of DePreSys 3 to simulate a northward shift of the ITCZ along with increased Sahel precipitation is likely to be associated to its ability to simulate the SAT decadal variability over the North Atlantic, and particular the SPG. Many studies have shown that extratropical SST anomalies can affect the tropical circulation through changes in atmospheric heat transport (Kang et al. 2008; Smith et al. 2010). This was supported in particular by Dunstone et al. (2011), which showed that an accurate simulation of SPG temperature variability is key to obtain skill in predicting temperature and precipitation over the subtropical North Atlantic Ocean in idealized experiments.

Associated with the both the observed and simulated changes in precipitation, the subtropical North Atlantic experiences a shift to an anomalously cyclonic (anticyclonic) 
Fig. 8 The difference in linearly detrended precipitation $\left(\mathrm{mm} \mathrm{day}^{-1}\right)$ in summer (JJAS) between the 1995-2014 minus the 1974-1994 periods for lead time 1 year and 2-5 years, for both GPCP $(\mathbf{a}, \mathbf{b})$ and DePreSys3 (c, d). North East Asia (NEA) is defined as the box represented in black: $\left(90^{\circ} \mathrm{E}-130^{\circ} \mathrm{E} ; 40^{\circ} \mathrm{N}-50^{\circ} \mathrm{N}\right)$. Dots indicate that anomalies are different to zero at the $95 \%$ confidence level according to a Student t-test. Note the different colour bars for $\operatorname{NCEP}(\mathbf{a}, \mathbf{b})$ and DePreSys3 (c, d)
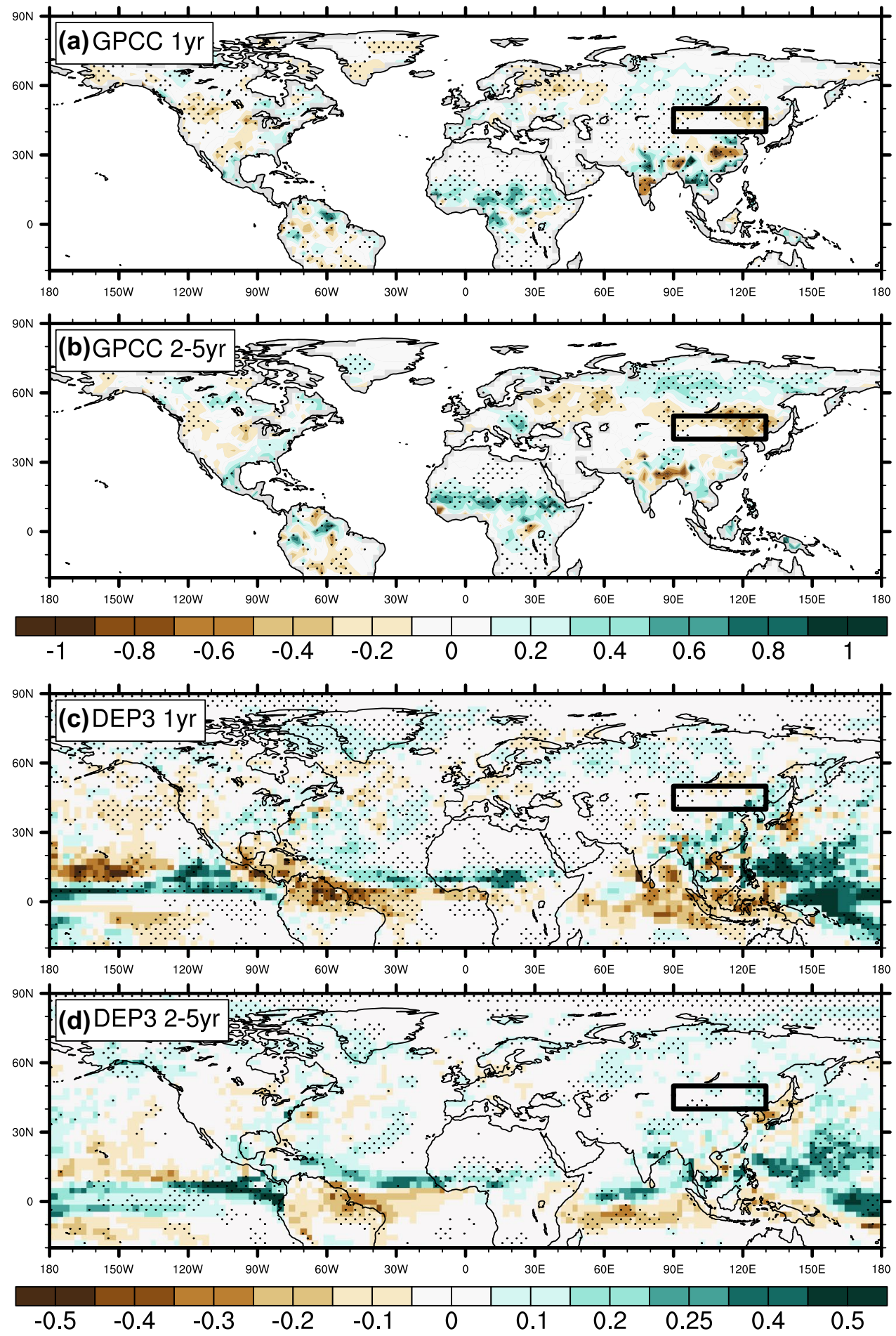

circulation at low-level (upper-level), as indicated by the Figs. 6 and 7, for both the 1 and 2-5 year lead-time. This baroclinic mode of the atmospheric circulation is consistent with a response to increased tropical precipitation through diabatic heating of the atmosphere (Hoskins et al. 1977; Hoskins and Karoly 1981; Lau 1997). We also found an increase in wind divergence at upper-level over the subtropical Atlantic Ocean (and over the Sahel in NCEP) in association with increased precipitation (not shown). Therefore, the results suggest that the warming over the North Atlantic Ocean excited the CGT pattern in DePreSys3, and, hence, modulated the surface temperature over Eurasia. Such a mechanism is consistent with (Liu and Chiang 2012), 
which highlighted the role of North Atlantic in triggering the CGT pattern.

\section{Discussion}

In this paper we have assessed the predictability of SAT over NEA and found substantial skill in DePreSys3 owing to the ability of the decadal prediction system to simulate the circumglobal teleconnection pattern variability. DePreSys3 is in good agreement with NCEP, especially for the 2-5 year lead-time. There are, however, some uncertainties, especially for the 1 year lead-time for which the change in atmospheric circulation at upper-level is not clearly apparent. These uncertainties are due to (1) the experimental methodology (i.e. sampling errors due to the initialization strategy), (2) the fidelity of the simulation and (3) other processes that may be important. These issues are discussed above:

- (1) The initialization of hindcasts every 2-3 years can lead to uncertainties in the representation of climate anomalies (e.g. differences with the AMV index in NCEP; as seen in Fig. 3e). Furthermore, Lin et al. (2016) found that both interdecadal and interannual CGT present a different vertical structure, although they both lead to a strong warming over East Asia. However, in the present study we cannot properly separate the interannual and interdecadal evolution of the CGT since hindcasts are initialized every 2-3 years (from 1960 to 2008), instead of every year, which limits our ability to elucidate the source of the CGT at either time-scale.

- We obtain a delay in phase in the AMV index in DePreSys3. We computed anomalies between two periods (1995-2010 minus 1979-1994, as in the next section), using NCEP and the Cowtan and Way (2014) dataset (CWT), with the entire time series and a sub-sample of data, and found that the sampling can impact the obtained changes in temperature (Fig. S12). Therefore, the number of hindcasts start dates (i.e. the sampling) is found to be an important issue in the assessment of the model performance. However, we assume that it is better to compare DePreSys3 and NCEP by analyzing them in a similar way, i.e. with the sub-sampled start-date.

- (2) Kosaka et al. (2012) showed that an accurate simulation of the Rossby waves is crucial for predicting SAT over East Asia. We test the reliability of the possible impact of North Atlantic on East Asia through the circumglobal teleconnection pattern in winter. For example, for winter we found similar results with DePreSys3 (e.g. increased precipitation over the subtropical North Atlantic Ocean associated with a Rossby wave, which led to increased geopotential height at upper-level over NEA) (not shown). This is, as in summer, associated with a warming over the North Atlantic Ocean, particularly the subpolar gyre. However this teleconnection is not found in NCEP in winter for both the first and the 2-5 year lead-time. This difference may contribute to the low skill in predicting SAT over NEA in winter (Figs. S8 and S9). Furthermore, we highlighted that in summer the observed and simulated CGT is slightly out of phase, particularly over Europe, which could affect the skill scores (see Fig. 6). Therefore, an accurate representation of the CGT pattern is important for predicting SAT.

- GPCC and GPCP show a decrease in precipitation over NEA after the mid-1990s, leading to a strengthened subsidence and a decreased cloud cover, which, hence, leads to increased incoming solar radiative flux (not shown) that contributes to the surface warming. Over NEA such a precipitation change is not seen in DePreSy3 (Fig. 8) (moreover DePreSys3 has low skill in predicting precipitation over NEA). This observed-modelled difference in precipitation can, in part, explain the difference in the magnitude of circulation change between NCEP and DePreSys3.

- (3) Extra-tropical SSTs could also impact Europe by triggering Rossby waves (Ghosh et al. 2016). The wave can then propagate further east reaching Asia. However, in this study we found a barotropic change over the northern Atlantic Ocean, showing that the Rossby wave is unlikely to be due to Extra-tropical SST changes. The impact of extra tropics on East Asia will be investigated in a further study (see conclusion).

- The complexity of the climate system means that teleconnections are not straightforward, and climate anomalies could have many competing causes. For instance, the AMV phase in the 1990s change do not appear to explain the Sahel precipitation recovery alone since Dong and Sutton (2015) have pointed out a role of greenhouse gases as well as anthropogenic aerosols (AA) emissions. Dong et al. (2016) have also highlighted the role of European emissions in anthropogenic aerosols in the recent summer warming over NEA. Indeed over the recent decades the emission in AA has decreased over Western Europe, leading to a surface warming through Europe to Asia (Bauer and Menon 2012; Dong et al. 2016). We analyzed the incoming shortwave radiation and found that the overestimated Northern Hemisphere warming (Fig. 5) can be due to anomalously strong incoming shortwave radiation due to decreased AA emissions over Europe and North Atlantic (Fig. S13). This is in line with Booth et al. (2012) which have suggested that anthropogenic aerosol emissions contribute to the observed variability of the North Atlantic Ocean. This warming over Europe can also be responsible for a part of the ZG250 change, and can, therefore, also impact East Asia in DePreSys3. 
(Kosaka et al. 2012) have for instance also highlighted that weather regimes (blocking) over Europe are additional sources of Rossby wave that can impact East Asia.

- For the 1 year lead-time we highlight a potential role of the Pacific Ocean in leading to skill in predicting SAT over Northeast Asia. Changes in precipitation and temperature over the western Pacific Ocean was found to be able to trigger the Pacific-Japan pattern, which can strongly impact East Asia's climate (Kosaka et al. 2011). It is interesting to note that the high frequency evolution of the CGT pattern has been associated with the PDO (Zhu et al. 2011; Nakamura and Miyama 2014; Lin et al. 2016). However, the composite analysis does not show a PDO pattern for DePreSys 3 at the first year lead-time (Fig. 5).

\section{Conclusion}

In this study we examine skill at capturing surface air temperature (SAT) in the DePreSys3 decadal prediction system. DePreSys 3 is based on a high-resolution ocean-atmosphere general circulation model, HadCM3-GC2, and is full-field initialized with start dates every 2-3 years from 1960 to 2008, and every year from 2009 to 2014 (a total of 26 start-dates). We focus on the skill at predicting surface-air temperature (SAT) over Northeast Asia (NEA) for 1 and 2-5 year lead-times, and on understanding the source of this prediction skill.

We find that DePreSys3 has significant skill at capturing surface temperature evolution over NEA, including skill when trends in SAT are removed. Furthermore, we find that the skill in predicting SAT over NEA is mainly due to the successful simulation of the strong multidecadal variability, rather than the inter-annual variability.

The multi-decadal evolution of SAT over NEA, which decreases during the 1960s and 1970s and increases during the 1990s is similar to that over the North Atlantic subpolar gyre where DePreSys3 also demonstrates skill in predicting SAT.

By focusing on the mid-1990s warming in both regions, we highlight that the multi-decadal variability in SAT in the North Atlantic subpolar gyre and NEA appear to be linked via upper-level atmospheric Rossby wave. Thus, we propose that skill in predicting low-frequency SAT variability over NEA is due to a mechanism, which can be summarized as follows:

1. The warming of the North Atlantic Ocean is associated with an increase in precipitation over the Sahel and the subtropical Atlantic Ocean.

2. The increase in precipitation triggers a Rossby wave through diabatic heating of the atmosphere.
3. The Rossby wave propagates eastward, following the upper-level subtropical jet, and modulates the upperlevel geopotential height from Europe to East Asia.

4. Anomalously positive geopotential height over NEA and associated upper-level anticyclonic circulation anomalies are associated with the warming at the surface over North-east Asia.

We show that NEA SAT can be modulated by variability in the North Atlantic via the CGT pattern. Hence, we argue that the high potential predictability of the SSTs over the North Atlantic Ocean (Pohlmann et al. 2004) is a source of predictability for the decadal to multi-decadal evolution of SAT over NEA. This is a promising result since changes of SAT relative to a long-term trend are difficult to predict over land (Bellucci et al. 2013; among others). This mechanism is found to be robust at a 2-5 year leadtime and is consistent with the literature (Wu et al. 2016a, b; Lin et al. 2016) and has been associated with changes over the Atlantic Ocean (Lu et al. 2006; Lin et al. 2016; Wu et al. 2016a, b; Wang et al. 2017). We also tested this mechanism in observations with a comparison between the previous positive phase of the AMV (1950-1965) and the last negative phase of the AMV (1979-1993) and found a similar result but with an opposite sign: a Rossby wave extends from the Atlantic Ocean leading to negative SAT anomalies over NEA (Fig. S14). This teleconnection between the AMV and Asia has been highlighted in paleoclimate studies (Feng and $\mathrm{Hu}$ 2008; Zhao et al. 2014) and appears to have become stronger since the mid-90s (Qian et al. 2014). This is also in-line with Dunstone et al. (2011), which have shown that decadal Atlantic SPG variability can drive tropical Atlantic variability (precipitation, ITCZ shift), highlighting the importance of an accurate initialization and prediction of temperature over the North Atlantic Ocean in decadal prediction systems.

As described in Sect. 4 the simulation of CGT is slightly different between DePreSys3 and NCEP, especially for the 1 year lead-time for which the CGT pattern does not stand out. Therefore, better predictions can be provided by improving the simulation of the Atlantic Ocean dynamics (e.g. the Atlantic Meridional Overturning Circulation; as discussed in Menary et al. (2016)) and the teleconnection between the Atlantic Ocean and North-east Asia. Moreover, the source of the observed and simulated CGT pattern is still uncertain due to the complexity of the climate system. Hence, the change of the CGT pattern has to be assessed in a further study by conducting controlled sensitivity experiments to further probe the impact of a warming Atlantic Ocean on North East Asia, by following the protocol described in Boer et al. (2016) for the Decadal Climate Prediction Project of the Climate Model Intercomparison Project, phase 6. 
Acknowledgements The authors gratefully acknowledge support from the UK-China Research and Innovation Partnership Fund through the Met Office Climate Science for Service Partnership (CSSP) China as part of the Newton Fund. BD, JR and RS were supported by the Natural Environment Research Council (NERC) via the National Centre for Atmospheric Science (NCAS), and JR was additionally funded by the NERC ACSIS program. We also thank Doug Smith, Leon Hermanson and The Met Office for providing the DePreSys3 output.

Open Access This article is distributed under the terms of the Creative Commons Attribution 4.0 International License (http://creativecommons.org/licenses/by/4.0/), which permits unrestricted use, distribution, and reproduction in any medium, provided you give appropriate credit to the original author(s) and the source, provide a link to the Creative Commons license, and indicate if changes were made.

\section{References}

Bauer SE, Menon S (2012) Aerosol direct, indirect, semidirect, and surface albedo effects from sector contributions based on the IPCC AR5 emissions for preindustrial and present-day conditions. J Geophys Res Atmos. doi:10.1029/2011JD016816

Bellucci A, Gualdi S, Masina S et al (2013) Decadal climate predictions with a coupled OAGCM initialized with oceanic reanalyses. Clim Dyn 40:1483-1497. doi:10.1007/s00382-012-1468-z

Bellucci A, Haarsma R, Gualdi S et al (2015) An assessment of a multi-model ensemble of decadal climate predictions. Clim Dyn 44:2787-2806. doi:10.1007/s00382-014-2164-y

Bernard B, Madec G, Penduff T et al (2006) Impact of partial steps and momentum advection schemes in a global ocean circulation model at eddy-permitting resolution. Ocean Dyn 56:543-567. doi:10.1007/s10236-006-0082-1

Best MJ, Pryor M, Clark DB et al (2011) The Joint UK Land Environment Simulator (JULES), model description—part 1: energy and water fluxes. Geosci Model Dev 4:677-699. doi:10.5194/ gmd-4-677-2011

Boer GJ (2000) A study of atmosphere-ocean predictability on long time scales. Clim Dyn 16:469-477. doi:10.1007/s003820050340

Boer GJ, Smith DM, Cassou C et al (2016) The decadal climate prediction project (DCPP) contribution to CMIP6. Geosci Model Dev 9:3751-3777. doi:10.5194/gmd-9-3751-2016

Booth BBB, Dunstone NJ, Halloran PR et al (2012) Aerosols implicated as a prime driver of twentieth-century North Atlantic climate variability. Nature 484:228-232. doi:10.1038/nature10946

Chen W, Lu R (2014) A decadal shift of summer surface air temperature over Northeast Asia around the mid-1990s. Adv Atmos Sci 31:735-742. doi:10.1007/s00376-013-3154-4

Chikamoto Y, Kimoto M, Ishii M et al (2013) An overview of decadal climate predictability in a multi-model ensemble by climate model MIROC. Clim Dyn 40:1201-1222. doi:10.1007/ s00382-012-1351-y

Collins M, Botzet M, Carril AF et al (2006) Interannual to decadal climate predictability in the North Atlantic: a multimodel-ensemble study. J Clim 19:1195-1203. doi:10.1175/JCLI3654.1

Cowtan K, Way RG (2014) Coverage bias in the HadCRUT4 temperature series and its impact on recent temperature trends. Q J R Meteorol Soc 140:1935-1944. doi:10.1002/qj.2297

Cox P, Stephenson D (2007) Climate change: a changing climate for prediction. Science 317:207-208. doi:10.1126/science.1145956

Dee DP, Uppala SM, Simmons AJ et al (2011) The ERA-Interim reanalysis: configuration and performance of the data assimilation system. Q J R Meteorol Soc 137:553-597. doi:10.1002/qj.828
Ding Q, Wang B (2005) Circumglobal teleconnection in the Northern Hemisphere summer. J Clim 18:3483-3505. doi:10.1175/ JCLI3473.1

Ding Q, Wang B, Wallace JM, Branstator G (2011) Tropical-extratropical teleconnections in boreal summer: observed interannual variability. J Clim 24:1878-1896. doi:10.1175/2011JCLI3621.1

Doblas-Reyes FJ, Andreu-Burillo I, Chikamoto Y et al (2013) Initialized near-term regional climate change prediction. Nat Commun 4:1715. doi: $10.1038 /$ ncomms 2704

Dong B, Sutton R (2015) Dominant role of greenhouse-gas forcing in the recovery of Sahel rainfall. Nat Clim Chang 5:757-760. doi: $10.1038 /$ nclimate 2664

Dong B, Sutton RT, Chen W et al (2016) Abrupt summer warming and changes in temperature extremes over Northeast Asia since the mid-1990s: drivers and physical processes. Adv Atmos Sci 33:1005-1023. doi:10.1007/s00376-016-5247-3

Dunstone NJ, Smith DM, Eade R (2011) Multi-year predictability of the tropical Atlantic atmosphere driven by the high latitude North Atlantic Ocean. Geophys Res Lett. doi:10.1029/2011GL047949

Dunstone N, Smith D, Scaife A et al (2016) Skilful predictions of the winter North Atlantic Oscillation one year ahead. Nat Geosci 9:809-814. doi:10.1038/ngeo2824

Enomoto T (2004) Interannual Variability of the Bonin high associated with the propagation of Rossby waves along the Asian Jet. J Meteorol Soc Jpn 82:1019-1034. doi:10.2151/jmsj.2004.1019

Enomoto T, Hoskins BJ, Matsuda Y (2003) The formation mechanism of the Bonin high in August. Q J R Meteorol Soc 129:157-178. doi:10.1256/qj.01.211

Feng S, Hu Q (2008) How the North Atlantic Multidecadal Oscillation may have influenced the Indian summer monsoon during the past two millennia. Geophys Res Lett 35:L01707. doi:10.1029 /2007GL032484

Gaetani M, Mohino E (2013) Decadal Prediction of the Sahelian precipitation in CMIP5 simulations. J Clim 26:7708-7719. doi:10.1175/JCLI-D-12-00635.1

Gao Z, Hu Z-Z, Jha B et al (2014) Variability and predictability of Northeast China climate during 1948-2012. Clim Dyn 43:787804. doi: 10.1007/s00382-013-1944-0

García-Serrano J, Guemas V, Doblas-Reyes FJ (2015) Added-value from initialization in predictions of Atlantic multi-decadal variability. Clim Dyn 44:2539-2555. doi:10.1007/s00382-014-2370-7

Ghosh R, Müller WA, Baehr J, Bader J (2016) Impact of observed North Atlantic multidecadal variations to European summer climate: a linear baroclinic response to surface heating. Clim Dyn. doi:10.1007/s00382-016-3283-4

Goddard L, Kumar A, Solomon A et al (2013) A verification framework for interannual-to-decadal predictions experiments. Clim Dyn 40:245-272. doi:10.1007/s00382-012-1481-2

Griffies SM, Bryan K (1997) Predictability of North Atlantic multidecadal climate variability. Science 275:181-184. doi:10.1126/ science.275.5297.181

Guemas V, Corti S, García-Serrano J et al (2013) The Indian Ocean: the region of highest skill worldwide in decadal climate prediction. J Clim 26:726-739. doi:10.1175/JCLI-D-12-00049.1

Han T, Chen H, Wang H (2015) Recent changes in summer precipitation in Northeast China and the background circulation. Int J Climatol 35:4210-4219. doi:10.1002/joc.4280

Hansen J, Ruedy R, Sato M, Lo K (2010) Global surface temperature change. Rev Geophys 48:RG4004. doi:10.1029/2010RG000345

Hibbard KA, Meehl GA, Cox PM, Friedlingstein P (2007) A strategy for climate change stabilization experiments. Eos Trans Am Geophys Union 88:217-221. doi:10.1029/2007EO200002

Hoskins BJ, Karoly DJ (1981) The steady linear response of a spherical atmosphere to thermal and orographic forcing. J Atmos Sci 38:1179-1196. doi:10.1175/1520-0469(1981)038<1179:TSLR $\mathrm{OA}>2.0 . \mathrm{CO} ; 2$ 
Hoskins BJ, Simmons AJ, Andrews DG (1977) Energy dispersion in a barotropic atmosphere. Q J R Meteorol Soc 103:553-567. doi: 10.1002/qj.49710343802

Huang R, Chen J, Wang L, Lin Z (2012) Characteristics, processes, and causes of the spatio-temporal variabilities of the East Asian monsoon system. Adv Atmos Sci 29:910-942. doi:10.1007/ s00376-012-2015-X

Hunke EC, Lipscomb WH (2004) The Los Alamos sea ice model, documentation and software. Version 3.1. Tech. rep. Los Alamos National Laboratory, NM

ICPO (2011) Data and bias correction for decadal climate predictions. International CLIVAR project office publication series 150:5. http://www.wcrp-climate.org/decadal/references/DCPP_Bias_ Correction.pdf

Kanamitsu M, Ebisuzaki W, Woollen J et al (2002) NCEP-DOE AMIP-II reanalysis (R-2). Bull Am Meteorol Soc 83:1631-1643. doi:10.1175/BAMS-83-11-1631

Kang SM, Held IM, Frierson DMW, Zhao M (2008) The response of the ITCZ to extratropical thermal forcing: idealized slab-ocean experiments with a GCM. J Clim 21:3521-3532. doi:10.1175/ 2007JCLI2146.1

Karspeck A, Yeager S, Danabasoglu G, Teng H (2015) An evaluation of experimental decadal predictions using CCSM4. Clim Dyn 44:907-923. doi:10.1007/s00382-014-2212-7

Keenlyside NS, Latif M, Jungclaus J et al (2008) Advancing decadalscale climate prediction in the North Atlantic sector. Nature 453:84-88. doi:10.1038/nature06921

Knight JR, Folland CK, Scaife AA (2006) Climate impacts of the Atlantic multidecadal oscillation. Geophys Res Lett 33:L17706. doi:10.1029/2006GL026242

Kosaka Y, Nakamura H (2010) Mechanisms of meridional teleconnection observed between a summer monsoon system and a subtropical anticyclone. Part I: the Pacific-Japan pattern. J Clim 23:5085-5108. doi:10.1175/2010JCLI3413.1

Kosaka Y, Xie S-P (2013) Recent global-warming hiatus tied to equatorial Pacific surface cooling. Nature 501:403-407

Kosaka Y, Xie S-P, Nakamura H (2011) Dynamics of interannual variability in summer precipitation over East Asia. J Clim 24:54355453. doi: 10.1175/2011JCLI4099.1

Kosaka Y, Chowdary JS, Xie S-P et al (2012) Limitations of seasonal predictability for summer climate over East Asia and the Northwestern Pacific. J Clim 25:7574-7589. doi:10.1175/ JCLI-D-12-00009.1

Kruschke T, Rust HW, Kadow C et al (2016) Probabilistic evaluation of decadal prediction skill regarding Northern Hemisphere winter storms. Meteorol Z 25:721-738. doi:10.1127/metz/2015/0641

Kwon M, Jhun J-G, Ha K-J (2007) Decadal change in east Asian summer monsoon circulation in the mid-1990s. Geophys Res Lett 34:L21706. doi:10.1029/2007GL031977

Lau N-C (1997) Interactions between global SST anomalies and the midlatitude atmospheric circulation. Bull Am Meteorol Soc 78:21-33. doi:10.1175/1520-0477(1997)078<0021:IBGSAA> 2.0.CO;2

Lin H (2009) Global extratropical response to diabatic heating variability of the Asian summer monsoon. J Atmos Sci 66:2697-2713. doi:10.1175/2009JAS3008.1

Lin J-S, Wu B, Zhou T-J (2016) Is the interdecadal circumglobal teleconnection pattern excited by the Atlantic multidecadal Oscillaon? Atmos Ocean Sci Lett 9:451-457. doi:10.1080/16742834 .2016 .1233800

Liu Y, Chiang JCH (2012) Coordinated abrupt weakening of the Eurasian and North African monsoons in the 1960s and links to extratropical North Atlantic cooling. J Clim 25:3532-3548. doi:10.1175/JCLI-D-11-00219.1

Lu R-Y, Oh J-H, Kim B-J (2002) A teleconnection pattern in upper-level meridional wind over the North
African and Eurasian continent in summer. Tellus A 54:44-55. doi:10.1034/j.1600-0870.2002.00248.x

Lu R, Dong B, Ding H (2006) Impact of the Atlantic multidecadal oscillation on the Asian summer monsoon. Geophys Res Lett 33:L24701. doi:10.1029/2006GL027655

MacLachlan C, Arribas A, Peterson KA et al (2015) Global seasonal forecast system version 5 (GloSea5): a high-resolution seasonal forecast system. Q J R Meteorol Soc 141:1072-1084. doi: $10.1002 / \mathrm{qj} .2396$

Madec G (2008) NEMO ocean engine. Note du Pole de modélisation, Institut Pierre-Simon Laplace (IPSL), France No 27, ISSN No: $1288-1619$

Martin ER, Thorncroft CD (2014) The impact of the AMO on the West African monsoon annual cycle. Q J R Meteorol Soc 140:31-46. doi:10.1002/qj.2107

Matei D, Pohlmann H, Jungclaus J et al (2012) Two tales of initializing decadal climate prediction experiments with the ECHAM5/ MPI-OM model. J Clim 25:8502-8523. doi:10.1175/ JCLI-D-11-00633.1

Meehl GA, Goddard L, Murphy J et al (2009) Decadal prediction. Bull Am Meteorol Soc 90:1467-1485. doi:10.1175/2009B AMS2778.1

Meehl GA, Teng H, Arblaster JM (2014) Climate model simulations of the observed early-2000s hiatus of global warming. Nat Clim Chang 4:898-902

Megann A, Storkey D, Aksenov Y et al (2014) GO5.0: the joint NERC-Met Office NEMO global ocean model for use in coupled and forced applications. Geosci Model Dev 7:1069-1092. doi:10.5194/gmd-7-1069-2014

Mehta VM, Wang H, Mendoza K (2013) Decadal predictability of tropical basin average and global average sea surface temperatures in CMIP5 experiments with the HadCM3, GFDL-CM2.1, NCAR-CCSM4, and MIROC5 global earth system models. Geophys Res Lett 40:2807-2812. doi:10.1002/grl.50236

Meinshausen M, Smith SJ, Calvin K et al (2011) The RCP greenhouse gas concentrations and their extensions from 1765 to 2300. Clim Change 109:213-241. doi:10.1007/ s10584-011-0156-Z

Menary MB, Hermanson L, Dunstone NJ (2016) The impact of Labrador sea temperature and salinity variability on density and the subpolar AMOC in a decadal prediction system. Geophys Res Lett 43(12):212-217,227. doi:10.1002/2016GL070906

Mochizuki T, Chikamoto Y, Kimoto M et al (2012) Decadal prediction using a recent series of MIROC global climate models. J Meteorol Soc Jpn 90A:373-383. doi:10.2151/jmsj.2012-A22

Mohino E, Keenlyside N, Pohlmann H (2016) Decadal prediction of Sahel rainfall: where does the skill (or lack thereof) come from? Clim Dyn 47:3593-3612. doi:10.1007/s00382-016-3416-9

Monerie P-A, Coquart L, Maisonnave É et al (2017) Decadal prediction skill using a high-resolution climate model. Clim Dyn. doi:10.1007/s00382-017-3528-x

Msadek R, Delworth TL, Rosati A et al (2014) Predicting a decadal shift in North Atlantic climate variability using the GFDL forecast system. J Clim 27:6472-6496. doi:10.1175/ JCLI-D-13-00476.1

Nakamura M, Miyama T (2014) Impacts of the Oyashio temperature front on the regional climate. J Clim 27:7861-7873. doi:10.1175/ JCLI-D-13-00609.1

Nicholson SE (2013) The West African Sahel: a review of recent studies on the rainfall regime and its interannual variability. ISRN Meteorol 2013:1-32. doi:10.1155/2013/453521

Nitta T (1987) Convective activities in the Tropical Western Pacific and their impact on the Northern Hemisphere summer circulation. J Meteorol Soc Japan Ser II 65:373-390. doi:10.2151/ jmsj1965.65.3_373 
Pohlmann H, Botzet M, Latif M et al (2004) Estimating the decadal predictability of a coupled AOGCM. J Clim 17:4463-4472. doi:10.1175/3209.1

Pohlmann H, Jungclaus JH, Köhl A et al (2009) Initializing decadal climate predictions with the GECCO oceanic synthesis: effects on the North Atlantic. J Clim 22:3926-3938. doi:10.1175/2009 JCLI2535.1

Pohlmann H, Smith DM, Balmaseda MA et al (2013) Predictability of the mid-latitude Atlantic meridional overturning circulation in a multi-model system. Clim Dyn 41:775-785. doi:10.1007/ s00382-013-1663-6

Qi L, Wang Y (2012) Changes in the observed trends in extreme temperatures over China around 1990. J Clim 25:5208-5222. doi:10.1175/JCLI-D-11-00437.1

Qian C, Yu J-Y, Chen G (2014) Decadal summer drought frequency in China: the increasing influence of the Atlantic multi-decadal oscillation. Environ Res Lett 9:124004. doi:10.1088/1748-9326/9/12/124004

Rayner NA, Parker DE, Horton EB et al (2003) Global analyses of sea surface temperature, sea ice, and night marine air temperature since the late nineteenth century. J Geophys Res 108:4407. doi: 10.1029/2002JD002670

Robson JI, Sutton RT, Smith DM (2012) Initialized decadal predictions of the rapid warming of the North Atlantic Ocean in the mid 1990s. Geophys Res Lett. doi:10.1029/2012GL053370

Robson J, Sutton R, Smith D (2014) Decadal predictions of the cooling and freshening of the North Atlantic in the 1960s and the role of ocean circulation. Clim Dyn 42:2353-2365. doi:10.1007/ s00382-014-2115-7

Rohde R, Muller A, Jacobsen R R, et al (2013) A new estimate of the average earth surface land temperature spanning 1753 to 2011 . Geoinf Geostat Overv. doi:10.4172/2327-4581.1000101

Sanogo S, Fink AH, Omotosho JA et al (2015) Spatio-temporal characteristics of the recent rainfall recovery in West Africa. Int $\mathrm{J}$ Climatol 35:4589-4605. doi:10.1002/joc.4309

Schneider U, Becker A, Finger P et al (2014) GPCC's new land surface precipitation climatology based on quality-controlled in situ data and its role in quantifying the global water cycle. Theor Appl Climatol 115:15-40. doi:10.1007/s00704-013-0860-x

Sheen KL, Smith DM, Dunstone NJ et al (2017) Skilful prediction of Sahel summer rainfall on inter-annual and multi-year timescales. Nat Commun 8:14966

Smith DM, Murphy JM (2007) An objective ocean temperature and salinity analysis using covariances from a global climate model. J Geophys Res 112:C02022. doi:10.1029/2005JC003172

Smith DM, Cusack S, Colman AW et al (2007) Improved surface temperature prediction for the coming decade from a global climate model. Science 317:796-799. doi:10.1126/science.1139540

Smith DM, Eade R, Dunstone NJ et al (2010) Skilful multi-year predictions of Atlantic hurricane frequency. Nat Geosci 3:846-849. doi:10.1038/ngeo1004

Smith DM, Allan RP, Coward AC et al (2015) Earth's energy imbalance since 1960 in observations and CMIP5 models. Geophys Res Lett 42:1205-1213. doi:10.1002/2014GL062669

Takaya K, Nakamura H (2001) A formulation of a phase-independent wave-activity flux for stationary and migratory quasigeostrophic eddies on a zonally varying basic flow. J Atmos Sci 58:608-627. doi:10.1175/1520-0469(2001)058<0608:AFOAPI > 2.0.CO;2

Taylor KE, Stouffer RJ, Meehl GA (2012) An overview of CMIP5 and the experiment design. Bull Am Meteorol Soc 93:485-498
Timmreck C, Pohlmann H, Illing S, Kadow C (2016) The impact of stratospheric volcanic aerosol on decadal-scale climate predictions. Geophys Res Lett 43:834-842. doi:10.1002/201 5GL067431

Trenberth KE, Shea DJ (2006) Atlantic hurricanes and natural variability in 2005. Geophys Res Lett. doi:10.1029/2006GL026894

Ueda H, Kamae Y, Hayasaki M et al (2015) Combined effects of recent Pacific cooling and Indian Ocean warming on the Asian monsoon. Nat Commun 6:8854. doi:10.1038/ncomms9854

Valcke S (2013) The OASIS3 coupler: a European climate modelling community software. Geosci Model Dev 6:373-388. doi:10.5194/gmd-6-373-2013

van Oldenborgh GJ, Doblas-Reyes FJ, Wouters B, Hazeleger W (2012) Decadal prediction skill in a multi-model ensemble. Clim Dyn 38:1263-1280. doi:10.1007/s00382-012-1313-4

Vose RS, Arndt D, Banzon VF et al (2012) NOAA's merged landocean surface temperature analysis. Bull Am Meteorol Soc 93:1677-1685. doi:10.1175/BAMS-D-11-00241.1

Walters DN, Williams KD, Boutle IA et al (2014) The met office unified model global atmosphere 4.0 and JULES global land 4.0 configurations. Geosci Model Dev 7:361-386. doi:10.5194/ gmd-7-361-2014

Wang H, Liu G, Chen J (2017) Contribution of the tropical western Atlantic thermal conditions during the preceding winter to summer temperature anomalies over the lower reaches of the Yangtze River basin-Jiangnan region. Int J Climatol. doi:10.1002/ joc.5111

Watanabe M, Kamae Y, Yoshimori M et al (2013) Strengthening of ocean heat uptake efficiency associated with the recent climate hiatus. Geophys Res Lett 40:3175-3179. doi:10.1002/grl.50541

Williams KD, Harris CM, Bodas-Salcedo A et al (2015) The Met Office Global coupled model 2.0 (GC2) configuration. Geosci Model Dev 8:1509-1524. doi:10.5194/gmd-8-1509-2015

Wu R, Wen Z, Yang S et al (2010) An interdecadal change in Southern China Summer rainfall around 1992/93. J Clim 23:2389-2403. doi:10.1175/2009JCLI3336.1

Wu B, Lin J, Zhou T (2016a) Interdecadal circumglobal teleconnection pattern during boreal summer. Atmos Sci Lett 17:446-452. doi:10.1002/asl.677

Wu B, Zhou T, Li T et al (2016b) Impacts of the Pacific-Japan and circumglobal teleconnection patterns on the interdecadal variability of the East Asian summer monsoon. J Clim 29:3253-3271. doi:10.1175/JCLI-D-15-0105.1

Yasui S, Watanabe M (2009) Forcing processes of the summertime circumglobal teleconnection pattern in a dry AGCM. J Clim 23:2093-2114. doi:10.1175/2009JCLI3323.1

Yeager S, Karspeck A, Danabasoglu G et al (2012) A decadal prediction case study: late twentieth-century North Atlantic Ocean heat content. J Clim 25:5173-5189. doi:10.1175/JCLI-D-11-00595.1

Zhao P, Jones P, Cao L et al (2014) Trend of surface air temperature in Eastern China and associated large-scale climate variability over the last 100 years. J Clim 27:4693-4703. doi:10.1175/ JCLI-D-13-00397.1

Zhu Y, Wang H, Zhou W, Ma J (2011) Recent changes in the summer precipitation pattern in East China and the background circulation. Clim Dyn 36:1463-1473. doi:10.1007/s00382-010-0852-9

Zhu C, Wang B, Qian W, Zhang B (2012) Recent weakening of northern East Asian summer monsoon: a possible response to global warming. Geophys Res Lett. doi:10.1029/2012GL051155 